\title{
Molecular and Morphological Configuration for 2-Arachidonoylglycerol-Mediated Retrograde Signaling at Mossy Cell-Granule Cell Synapses in the Dentate Gyrus
}

\author{
Motokazu Uchigashima, ${ }^{1}$ Maya Yamazaki, ${ }^{2}$ Miwako Yamasaki, ${ }^{1}$ Asami Tanimura, ${ }^{3}$ Kenji Sakimura,,${ }^{2,4}$ Masanobu Kano, ${ }^{3}$ \\ and Masahiko Watanabe ${ }^{1,4}$ \\ ${ }^{1}$ Department of Anatomy, Hokkaido University School of Medicine, Sapporo 060-8638, Japan, ${ }^{2}$ Department of Cellular Neurobiology, Brain Research \\ Institute, Niigata University, Niigata 951-8585, Japan, ${ }^{3}$ Department of Neurophysiology, Graduate School of Medicine, University of Tokyo, Tokyo 113- \\ 0033, Japan, and 4Japan Science and Technology Agency, Core Research for Evolutional Science and Technology, Sanbocho, Chiyoda-ku, Tokyo 102-0075, \\ Japan
}

2-Arachidonoylglycerol (2-AG) is the endocannabinoid that mediates retrograde suppression of neurotransmission in the brain. In the present study, we investigated the 2-AG signaling system at mossy cell (MC)- granule cell (GC) synapses in the mouse dentate gyrus, an excitatory recurrent circuit where endocannabinoids are thought to suppress epileptogenesis. First, we showed by electrophysiology that 2-AG produced by diacylglycerol lipase $\alpha(\mathrm{DGL} \alpha)$ mediated both depolarization-induced suppression of excitation and its enhancement by group I metabotropic glutamate receptor activation at MC-GC synapses, as they were abolished in DGL $\alpha$-knock-out mice. Immunohistochemistry revealed that DGL $\alpha$ was enriched in the neck portion of GC spines forming synapses with MC terminals, whereas cannabinoid $\mathrm{CB}_{1}$ receptors accumulated in the terminal portion of $\mathrm{MC}$ axons. On the other hand, the major 2-AG-degrading enzyme, monoacylglycerol lipase (MGL), was absent at MC-GC synapses but was expressed in astrocytes and some inhibitory terminals. Serial electron microscopy clarified that a given GC spine was innervated by a single MC terminal and also contacted nonsynaptically by other MC terminals making synapses with other GC spines in the neighborhood. MGL-expressing elements, however, poorly covered GC spines, amounting to $17 \%$ of the total surface of GC spines by astrocytes and $4 \%$ by inhibitory terminals. Our findings provide a basis for 2-AG-mediated retrograde suppression of MC-GC synaptic transmission and also suggest that 2-AG released from activated GC spines is readily accessible to nearby MC-GC synapses by escaping from enzymatic degradation. This molecular-anatomical configuration will contribute to adjust network activity in the dentate gyrus after enhanced excitation.

\section{Introduction}

Endocannabinoids (eCBs) are released from postsynaptic neurons, act retrogradely on presynaptic cannabinoid $\mathrm{CB}_{1}$ receptors, and induce short- and long-term suppression of transmitter release (Hashimotodani et al., 2007b; Kano et al., 2009). This retrograde signaling is triggered by depolarization-induced intracellular $\mathrm{Ca}^{2+}$ elevation (Kreitzer and Regehr, 2001; OhnoShosaku et al., 2001; Wilson and Nicoll, 2001), G $\alpha_{\mathrm{q} / 11 \text {-coupled }}$ receptor activation (Maejima et al., 2001), or both (Varma et al.,

\footnotetext{
Received Oct. 28, 2010; revised March 7, 2011; accepted April 4, 2011

Author contributions: M.U., M.K., and M.W. designed research; M.U. and A.T. performed research; Maya Yamazaki, Mi.Y., and K.Y. contributed unpublished reagents/analytic tools; M.U. and A.T. analyzed data; M.U., M.K., and M.W. wrote the paper.

This work was supported by Grants-in-Aid for Scientific Research (19100005 to M.W., 21220006 to M.K. 21300118 to K.S., 20-04030 to M.U.) and by the Strategic Research Program for Brain Sciences (Development of Biomarker Candidates for Social Behavior) and the Global COE Program (Integrative Life Science Based on the Study of Biosignaling Mechanisms) provided by Ministry of Education, Culture, Sports, Science and Technology, Japan. M.U. is a recipient of research fellowships from the Japan Society for the Promotion of Science for Young Scientists. We thank Taisuke Miyazaki for helpful comments.

Correspondence should be addressed to Masahiko Watanabe, Department of Anatomy, Hokkaido University School of Medicine, Sapporo 060-8638, Japan. E-mail: watamasa@med.hokudai.ac.jp.

DOI:10.1523/JNEUROSCI.5665-10.2011

Copyright $\odot 2011$ the authors $\quad 0270-6474 / 11 / 317700-15 \$ 15.00 / 0$
}

2001; Ohno-Shosaku et al., 2002; Hashimotodani et al., 2005), and is involved in various neural functions, such as learning and memory, analgesia, and neuroprotection (Kano et al., 2009). 2-Arachidonoylglycerol (2-AG) is the major eCB in the brain (Mechoulam et al., 1995; Sugiura et al., 1995; Stella et al., 1997) and is synthesized by sn- 1 diacylglycerol lipase $\alpha$ (DGL $\alpha$ ) in postsynaptic elements (Bisogno et al., 2003; Katona et al., 2006; Yoshida et al., 2006; Gao et al., 2010; Tanimura et al., 2010). 2-AG is degraded mainly by monoacylglycerol lipase (MGL) (Dinh et al., 2002; Blankman et al., 2007; Schlosburg et al., 2010), which is expressed in presynaptic terminals (Gulyas et al., 2004) and regulates the magnitude and time course of 2-AG-mediated retrograde signaling (Hashimotodani et al., 2007a; Pan et al., 2009). These molecular components are well orchestrated at individual synapses with some variations according to neuronal and synaptic organization (Kano et al., 2009).

Mossy cell (MC)-granule cell (GC) synapses in the dentate gyrus constitute an excitatory recurrent circuit in the pathway from the entorhinal cortex to the hippocampal CA3 and are considered as one of the epileptogenic circuits (Ratzliff et al., 2002). $\mathrm{CB}_{1}$ is particularly enriched at MC-GC synapses compared with other excitatory synapses in the hippocampus, and $\mathrm{CB}_{1}$ in hip- 
pocampal excitatory neurons plays a protective role against seizures (Kawamura et al., 2006; Monory et al., 2006; Katona and Freund, 2008). Experimental seizures lead to increased hippocampal levels of 2-AG and anandamide, another major eCB (Marsicano et al., 2003; Wallace et al., 2003; Wettschureck et al., 2006). Whereas DGL $\alpha$ is expressed at MC-GC synapses (Katona et al., 2006), anandamide is involved in non- $\mathrm{CB}_{1}$-mediated signaling in the dentate gyrus (Chávez et al., 2010). These lines of evidence suggest that 2-AG-mediated control of MC-GC synaptic activity plays a role in prevention of epileptogenesis. However, our understanding on how 2-AG-mediated signaling molecules are arranged at and around MC-GC synapses is still fragmental.

In the present study, we investigated the 2-AG-mediated signaling system at MC-GC synapses. We show that $2-\mathrm{AG}$ produced by DGL $\alpha$ is essential for depolarization-induced suppression of excitation (DSE) and its enhancement by the group I metabotropic glutamate receptor (mGluR). DGL $\alpha$ and $\mathrm{CB}_{1}$ highly accumulate on GC spines and MC terminals, respectively, whereas MGL is absent in MC-GC synapses. Ultrastructural reconstruction of MC-GC synapses reveals that a given GC spine is innervated by a single $\mathrm{MC}$ terminal and further contacted nonsynaptically by other MC terminals making synaptic contacts with other GC spines. This configuration will be a molecular-anatomical basis for 2-AG-mediated retrograde suppression of MC-GC synaptic transmission and also predicts its 2-AG-mediated cross talk to other MC-GC synapses in the neighborhood.

\section{Materials and Methods}

Animal and tissue preparation. All experiments were performed according to the guidelines for the care and use of laboratory animals of Hokkaido University, Niigata University, and the University of Tokyo. We used adult C57BL/6N, DGL $\alpha$-knock-out (Tanimura et al., 2010), and MGL-knock-out mice. MGL-knock-out mice were produced by homologous recombination using the embryonic stem (ES) cell line RENKA, which was derived from the C57BL/6N strain (Mishina and Sakimura, 2007). Targeting vector construct contained the exon 3 of the Mgll gene including one of the residues of the putative catalytic triad Ser-122 (Karlsson et al., 1997), with the $5.3 \mathrm{~kb}$ upstream, $4.6 \mathrm{~kb}$ downstream homologous genomic DNA and diphtheria toxin gene as a negative selection (supplemental Fig. S1A, available at www.jneurosci.org as supplemental material). Mgll genomic DNA fragments were amplified by PCR and were sequenced. The DNA fragment, which carried the $34 \mathrm{bp}$ loxP sequence and pgk-1 promoterdriven neomycin phosphotransferase gene (neo) flanked by two Flp recognition target (frt) sites, was inserted into the site $330 \mathrm{bp}$ upstream of exon 3 . The other loxP site was introduced into the site $280 \mathrm{bp}$ downstream of exon 3 to eliminate exon 3 after Cre-mediated recombination. This results in a frame-shift mutation in the Mgll gene.

ES cells were cultured, and a homologous recombinant clone was used to yield chimeric mice as described previously (Fukaya et al., 2006). Homologous recombinants were identified by Southern blot analysis (supplemental Fig. 1B, available at www.jneurosci.org as supplemental material) under the following conditions: EcoRI-digested DNA hybridized with $5^{\prime}$ probe, $22 \mathrm{~kb}$ for wild-type and $8.8 \mathrm{~kb}$ for targeted alleles; EcoRI-digested DNA hybridized with $3^{\prime}$ probe, $22 \mathrm{~kb}$ for wild-type and $15.6 \mathrm{~kb}$ for targeted alleles; AflII-digested DNA hybridized with neo probe, $9.6 \mathrm{~kb}$ for targeted allele. Chimeric mice were mated to C57BL/6N mice, and offspring were further crossed with TLCN-Cre mice (Nakamura et al., 2001; Fuse et al., 2004) to yield heterozygous mice. TLCN-Cre mice had been backcrossed to $\mathrm{C} 57 \mathrm{BL} / 6 \mathrm{~N}$ mice over 10 generations. Heterozygous $(+/-)$ mice were bred to each other to generate homozygous knock-out mice in addition to eliminating the introduced Cre gene from the line. The first offspring was genotyped by Southern blotting (supplemental Fig. S1C, available at www.jneurosci.org as supplemental material) under the following conditions; AflII-digested DNA hybridized with $5^{\prime}$ probe, $7.7 \mathrm{~kb}$ for wild-type and $6.9 \mathrm{~kb}$ knock-out alleles. Genotypes for all subsequent breeding were determined by PCR analysis of digested mouse tail samples. PCR

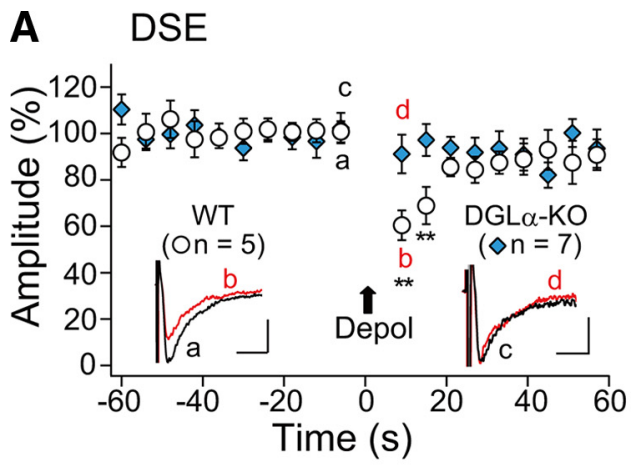

B DSE enhancement by DHPG
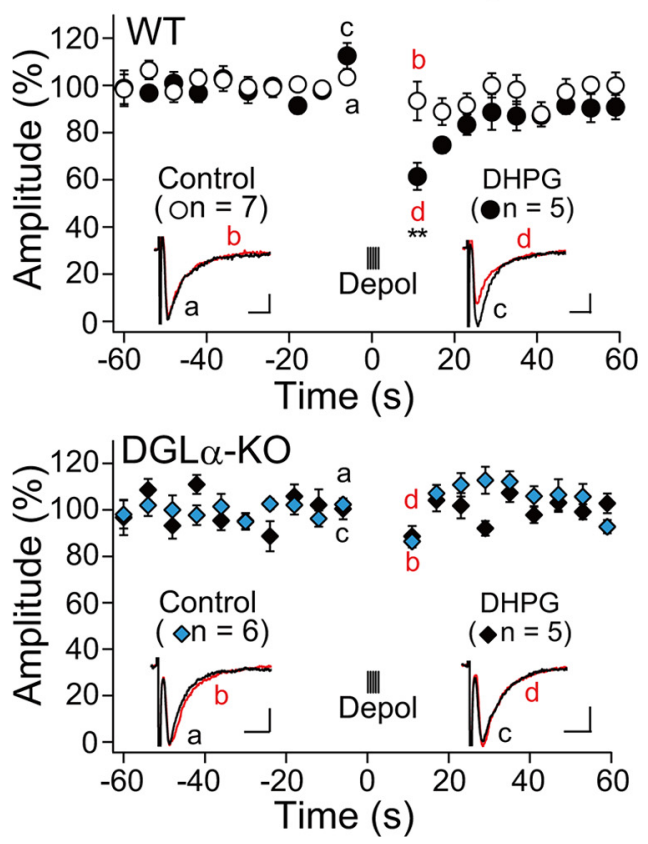

Figure 1. Retrograde suppression of excitation is absent at $M C-G C$ synapses in the dentate gyrus of DGL $\alpha$-knock-out mice. $A$, Sample traces and average time courses of the amplitudes of MC-GC EPSCs of wild-type (WT; open circles) and DGL $\alpha$-knock-out (KO) mice (blue diamonds) before and after depolarization (from -70 to $0 \mathrm{mV}$, for $3 \mathrm{~s}$ ). $\boldsymbol{B}$, Top, Retrograde suppression at $\mathrm{MC}-\mathrm{GC}$ synapses after combined depolarization (5 depolarization pulses from -70 to $0 \mathrm{mV}$ with $100 \mathrm{~ms}$ duration at $1 \mathrm{~Hz}$ ) with bath application of DHPG $(10 \mu \mathrm{m})$ in wild-type mice (filled circles). Note that depolarization alone failed to induce noticeable suppression (open circles). Bottom, No suppression was induced by either depolarization alone (blue diamonds) or combined depolarization with DHPG application (filled diamonds) at MC-GC synapses of DGL $\alpha$-KO mice. Protocols of depolarization and DHPG application were the same as in wild-type mice. Sample EPSC traces $(a-d)$ were obtained at the time points indicated in the graphs. Calibration: $\boldsymbol{A}, 100 \mathrm{pA}, 5 \mathrm{~ms}$ (WT) and $50 \mathrm{pA}, 5 \mathrm{~ms}$ (DGL $\alpha-K 0) ; \boldsymbol{B}, 20 \mathrm{pA}, 5 \mathrm{~ms}$ (WT) and $50 \mathrm{pA}, 5 \mathrm{~ms}$ (DGL $\alpha-K 0)$ ) ${ }^{* *} p<0.001$ (two-factor repeated-measures ANOVA followed by post hoc Bonferroni test).

genotyping of mouse tail DNA was performed with the following primers: Mgl-forward, 5'-GTGATCTCCTAATGCTGCAG-3'; Mgl-reverse, 5' GTTCTCAGACCTCTGCTAGC-3' (supplemental Fig. S1A, arrows, available at www.jneurosci.org as supplemental material). PCR products were 970 and 250 bp for the wild-type or MGL-knock-out allele, respectively (supplemental Fig. S1D, available at www.jneurosci.org as supplemental material). The loss of MGL in MGL-knock-out mouse brains was confirmed by isotopic in situ hybridization (supplemental Fig. $1 E$ ) and immunoblot (supplemental Fig. $1 F$, available at www.jneurosci.org as supplemental material). In each analysis, data were obtained from at least two male mice. We used wild-type and knock-out littermates in the present experiments.

Under deep pentobarbital anesthesia (100 mg/kg body weight, i.p.), mice were fixed by transcardial perfusion with $4 \%$ paraformaldehyde in $0.1 \mathrm{~m}$ phosphate buffer ( $\mathrm{PB}$; pH 7.2) for light microscopy, $4 \%$ paraformaldehyde/0.1-0.5\% glutaraldehyde in $0.1 \mathrm{M} \mathrm{PB}$ for immunoelectron 


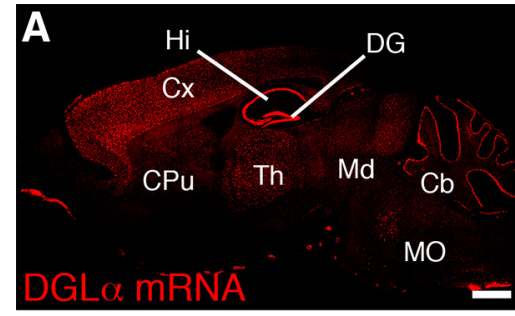

B

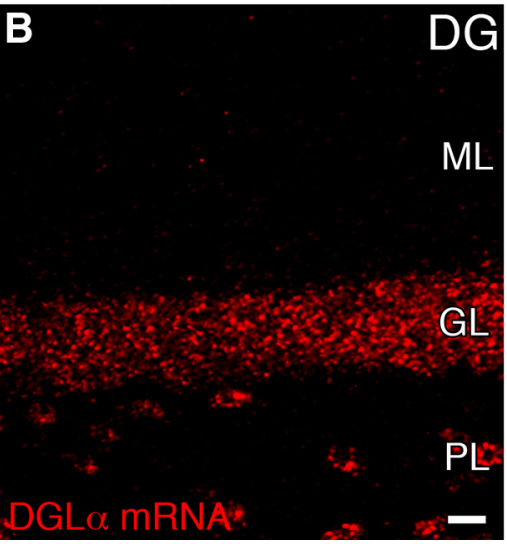





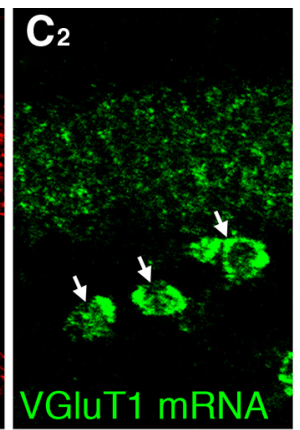
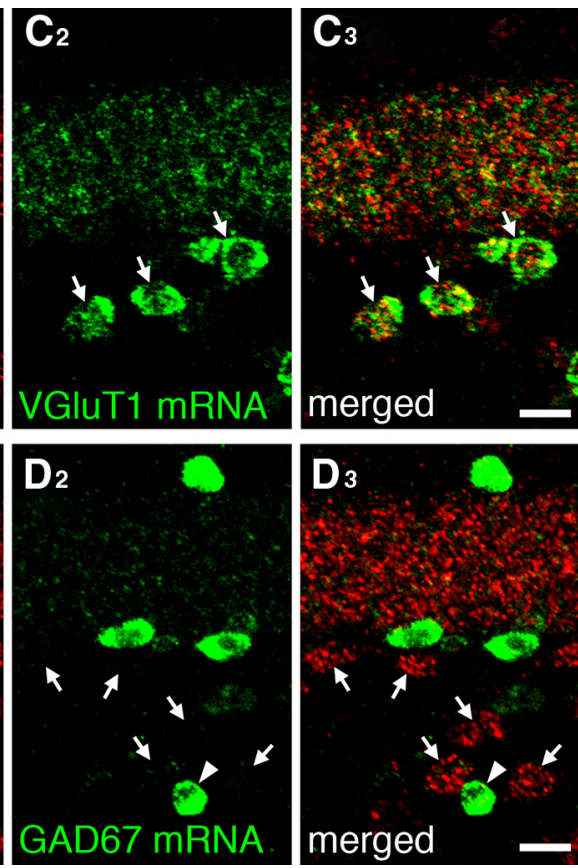

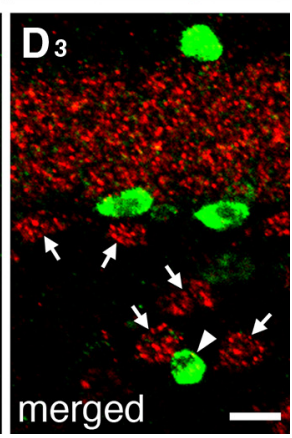

Figure 2. DGL $\alpha$ is highly expressed in GCS and MCs of the dentate gyrus. Fluorescent in situ hybridization (FISH) for DGL $\alpha$ mRNA is shown. $\boldsymbol{A}, \boldsymbol{B}$, Single FISH in the mouse brain ( $\boldsymbol{A}$ ) and dentate gyrus (DG; $\boldsymbol{B}$ ). Note the strong signals in the pyramidal cell layer of the hippocampus (Hi) and the GC layer (GL) of the DG. Hilar cells also express DGL $\alpha$ mRNA in the polymorphic layer (PL) of the DG. $\boldsymbol{C}, \boldsymbol{D}$, Double FISH for DGL $\alpha$ (red) and VGluT1 (C, green) or GAD67 (D, green) mRNAs. Hilar cells expressing DGL $\alpha$ mRNA at high levels (C, D, arrows) coexpress VGluT1 mRNA, but not GAD67 mRNA, indicating prominent expressions of DGL $\alpha$ mRNA in MCs. Low levels of DGL $\alpha$ mRNA are detected in some cells expressing GAD67 mRNA (D, arrowheads). Cb, Cerebellum; CPu, caudate-putamen; Cx, neocortex; Md, midbrain; M0, medulla oblongata; Th, thalamus, ML, molecular layer. Scale bars: $\boldsymbol{A}, 1 \mathrm{~mm} ; \boldsymbol{B}-\boldsymbol{D}, 20 \mu \mathrm{m}$.

microscopy, or $2 \%$ paraformaldehyde $/ 2 \%$ glutaraldehyde in 0.1 м PB for electron microscopy. Thick sections ( $50 \mu \mathrm{m}$ in thickness) were prepared with a microslicer (VT1000S; Leica) and subjected to the free-floating method, whereas semithin cryosections $(200 \mathrm{~nm})$ were prepared with an ultracryomicrotome (EM-FCS; Leica) and mounted on silane-coated glass slides. For in situ hybridization, brains were removed from the skull under deep pentobarbital anesthesia and frozen in powdered dry ice. Fresh frozen sections $(20 \mu \mathrm{m})$ were prepared with a cryostat (CM1900; Leica).

Fluorescent in situ hybridization. We used the following fluorescein- or digoxigenin (DIG)-labeled riboprobes: mouse DGL $\alpha$ (nucleotides 3311020 and 2176-3220; National Center for Biotechnology Information (NCBI) reference sequence NM_198114), mouse MGL (nucleotides 3941263; NCBI reference sequence NM_011844), mouse type 1 vesicular glutamate transporter (VGluT1; nucleotides 301-1680; GenBank accession number BC054462), mouse $67 \mathrm{kDa}$ glutamic acid decarboxylase (GAD67; nucleotides 1036-2015; NCBI reference sequence NM_008077), and mouse glutamate/aspartate transporter (GLAST; nucleotides 1571-2473; GenBank accession number AF330257). Probe synthesis and in situ hybridization were performed as described previously (Yamasaki et al., 2010). Briefly, fresh frozen sections were treated at room temperature with the following incubations: fixation, acetylation, and prehybridization in a hybridization buffer containing 50\% formamide, $50 \mathrm{~mm}$ Tris- $\mathrm{HCl}, \mathrm{pH} 7.5,0.02 \%$ Ficoll, $0.02 \%$ polyvinylpyrrolidone, $0.02 \%$ bovine serum albumin (BSA), $0.6 \mathrm{M} \mathrm{NaCl}$, $0.25 \%$ SDS, $200 \mathrm{mg} / \mathrm{ml}$ tRNA, $1 \mathrm{~mm}$ EDTA, and 10\% dextran sulfate. Hybridization was performed overnight at $63.5^{\circ} \mathrm{C}$ in the hybridization buffer with riboprobes diluted at 1:1000. After a stringent wash and blocking, fluorescein-labeled riboprobes were detected using a peroxidase-conjugated anti-fluorescein antibody (Roche Diagnostics) and the FITC-TSA plus amplification kit (PerkinElmer). After inactivation of residual peroxidase activity, DIG-labeled riboprobes were then detected using a peroxidase-conjugated anti-DIG antibody (Roche Diagnostics) and the Cy3-TSA plus kit (PerkinElmer). Nuclear counterstaining was done with TOTO3 (Invitrogen). Images were taken with a confocal laser-scanning microscope (FV1000; Olympus).

The specificity of hybridization signals was confirmed by blank labeling with use of sense riboprobes in all experiments, as reported previously (Yamasaki et al., 2010; Yamazaki et al., 2010). We also confirmed the specificity of DGL $\alpha$ mRNA signals by identical patterns with use of two nonoverlapping probes and that of MGL mRNA signals by significant reduction in MGL-knock-out mice (supplemental Fig. S2, available at www. jneurosci.org as supplemental material). Residual signals in MGL-knockout mice may reflect the expression and detection of truncated MGL mRNA lacking nucleotide residues encoded by exon 3. Cells expressing given mRNAs at high or low levels were defined as those having perikarya with or without individual fluorescent puncta merging into aggregates, respectively.

Isotopic in situ hybridization. Antisense oligonucleotide probes for MGL [5'-gcaccgcccatggagtggcccaggaggaagatggggacgtcgggg-3' (704-752; NM_ $011844)]$ were synthesized. They were radiolabeled with $\left[{ }^{33} \mathrm{P}\right] \mathrm{dATP}$ using terminal deoxyribonucleotidyl transferase (Invitrogen). Fresh frozen sections were hybridized with the radiolabeled probes as described previously (Uchigashima et al., 2007a,b). Hybridized sections were exposed to BioMax film (Kodak).

Antibody. We used affinity-purified primary antibodies raised against the following molecules (species immunized): MGL (rabbit; see below), DGL $\alpha$ [rabbit (Yoshida et al., 2006)], mGluR5 [guinea pig and goat (Uchigashima et al., 2007a)], MAP2 [rabbit and goat (Miura et al., 2006)], synaptophysin [guinea pig (Fukaya and Watanabe, 2000)], $\mathrm{CB}_{1}$ receptor [guinea pig (Fukudome et al., 2004)], calretinin [mouse (MAB1568; Millipore Bioscience Research Reagents), rabbit (Miyazaki et al., 2011)], VGluT1 [rabbit and goat (Miyazaki et al., 2003; Miura et al., 2006)], VGluT2 [guinea pig and goat (Miyazaki et al., 2003; Miura et al., 2006)], vesicular inhibitory amino acid transporter [VIAAT; goat (Miyazaki et al., 2003; Miura et al., 2006)], vesicular acetylcholine transporter [VAChT; rabbit (Nakamura et al., 2004)], glial fibrillary acidic protein [GFAP; guinea pig (Hisano et al., 2009)], GLAST [goat (Shibata et al., 1997)], 2',3'-cyclic nucleotide 3' phosphodiesterase (CNPase; mouse; C5922; Sigma), and Ibal (rabbit; Wako). For production of the MGL antibody, a cDNA fragment encoding the N-terminal 35 amino acids (NCBI reference sequence NM_011844) was subcloned into BamHI/EcoRI site of pGEX4T-2 plasmid (GE Healthcare) for expression of glutathione $S$-transferase fusion proteins. Immunization and affinity purification were performed as reported previously (Watanabe et al., 1998).

Immunohistochemistry. All immunohistochemical incubations were done at room temperature. For immunofluorescence, microslicer sec- 

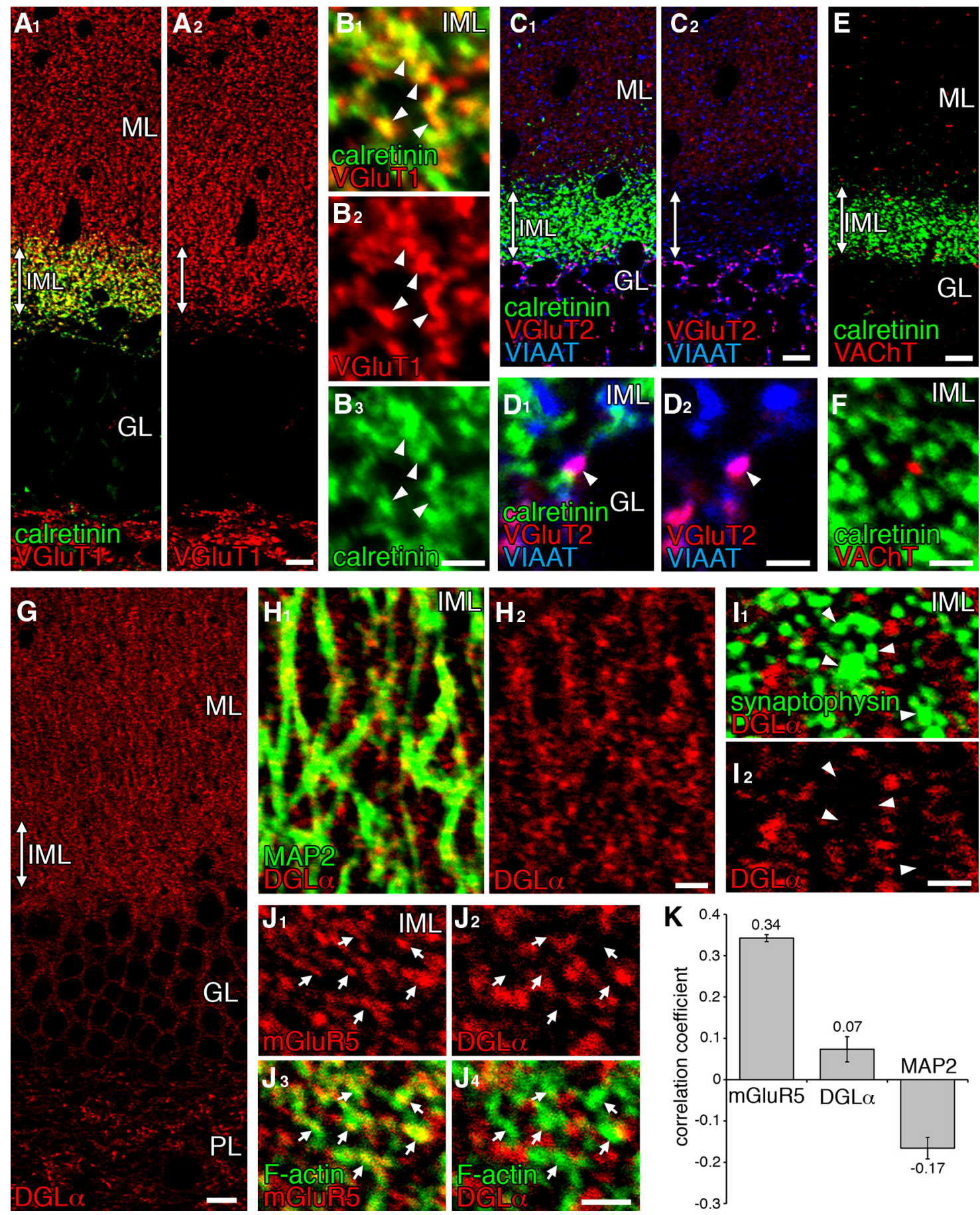

Figure 3. Distribution of MC terminals ( $\boldsymbol{A}-\boldsymbol{F})$ and immunofluorescence for $\mathrm{DGL} \alpha(\boldsymbol{G}-\boldsymbol{K})$ in the inner molecular layer of the dentate gyrus. $\boldsymbol{A}, \boldsymbol{B}$, Double immunofluorescence for VGluT1 (red) and calretinin (green). VGluT1-positive boutons are densely distributed and exclusively colabeled for calretinin in the inner molecular layer (IML; $\boldsymbol{B}$, arrowheads). $\boldsymbol{C}, \boldsymbol{D}$, Triple immunofluorescence for VGuT2 (red), VIAAT (blue), and calretinin (green). $\boldsymbol{E}, \boldsymbol{F}$, Double immunofluorescence for VAChT (red) and calretinin (green). Note that VGluT2/VIAAT-positive terminals from the supramammillary nucleus ( $\boldsymbol{C}, \boldsymbol{D}$, arrowheads) or VAChT-positive cholinergic terminals $(\boldsymbol{E}, \boldsymbol{F}$, arrowheads) are negative for calretinin and sparsely distributed in the MC-recipient IML. $\mathbf{G}-\boldsymbol{J}$, Immunofluorescence for DGL $\alpha$. G, Single immunofluorescence reveals dense punctate immunolabeling for $D G L \alpha$ all over the molecular layer (ML). $\boldsymbol{H}$, Double immunofluorescence for DGL $\alpha$ (red) and somatodendritic marker MAP2 (green) in the IML. Tiny punctate labeling for DGL $\alpha$ is distributed along MAP2-labeled dendrites. I, Double immunofluorescence for DGL $\alpha$ (red) and terminal marker synaptophysin

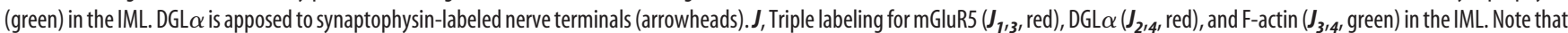
F-actin (arrows) is overlapped well with mGluR5 but aligned side by side with DGL $\alpha$. $K$, Summary bar graph showing the mean correlation coefficient of two fluorescent signals: between F-actin and mGluR5 (left), between F-actin and DGL $\alpha$ (middle), and between F-actin and MAP2 (right). The numbers and error bars indicate the mean correlation coefficient and SEM, respectively. Seven sets of images were analyzed for each pair. GL, GC layer. Scale bars: $A, C, E, G, 10 \mu \mathrm{m} ; \boldsymbol{B}, D, F, H-J, 2 \mu \mathrm{m}$.

tions and semithin cryosections were incubated successively with $10 \%$ normal donkey serum for $20 \mathrm{~min}$, a mixture of primary antibodies overnight $(1 \mu \mathrm{g} / \mathrm{ml})$, and a mixture of Alexa488-, indocarbocyanine (Cy3)-, and indodicarbocyanine (Cy5)-labeled species-specific secondary antibodies for $2 \mathrm{~h}$ at a dilution of 1:200 (Invitrogen, Jackson Immunoresearch). For the detection of filamentous (F)-actin, Alexa488-conjugated phalloidin (1:500; Invitrogen) was added to a mixture of secondary antibodies. For unknown reasons, we occasionally encountered cross-reaction of the 
MGL antibody to other primary antibodies when used in mixture. Therefore, we adopted the two-step method for multiple immunofluorescence involving MGL, as follows. First, MGL was detected with a rabbit MGL antibody and a Cy3-labeled rabbit-specific secondary antibody. After blocking with 10\% rabbit normal serum, other molecules were detected by incubation with non-rabbit primary antibodies followed by reaction with Alexa488- or Cy5labeled species-specific secondary antibodies. Images were taken with a fluorescent microscope (AX-70; Olympus Optical) equipped with a digital camera (DP70; Olympus Optical) or with a confocal laser-scanning microscope (FV1000; Olympus Optical). To minimize sampling bias, we used 5-10 images taken randomly. To evaluate the degree of overlap between two fluorescent signals (see Fig. $3 K$ ), we calculated, using MetaMorph software (Molecular Devices), the Pearson correlation coefficient, which yields values from -1 (a perfect negative correlation) to +1 (a perfect positive correlation).

For preembedding immunogold electron microscopy, microslicer sections were blocked with $5 \%$ BSA/0.02\% saponin/Tris-buffered saline (TBS; pH 7.5) for $30 \mathrm{~min}$ and incubated overnight with the primary antibody diluted with $1 \%$ BSA $/ 0.004 \%$ saponin/TBS. Sections were washed with $0.004 \%$ saponin/TBS and incubated with the secondary antibody linked to $1.4 \mathrm{~nm}$ gold particles (Nanogold; Nanoprobes) for $2 \mathrm{~h}$. After washing and postfixation with $1 \%$ glutaraldehyde for $10 \mathrm{~min}$, immunogold particles were intensified with a silver enhancement kit (HQ silver; Nanoprobes). Sections were treated with $1 \%$ osmium tetroxide $/ 0.1 \mathrm{M}$ PB for 15 min, stained in block with $2 \%$ uranyl acetate for $20 \mathrm{~min}$, and embedded in Epon 812. Photographs were taken with an H-7100 electron microscope (Hitachi).

Each profile of elements was identified based on the previous description with serial sections (Peters et al., 1976). To evaluate intraspine distribution of DGL $\alpha$, those spines whose head portion had a synaptic contact and neck portion was connected to the dendritic shaft were collected. On electron micrographs, we measured the length of the cell membrane, the cytoplasmic area, and the number or distribution of metal particles in each profile using MetaMorph software (Molecular Devices).

Electron microscopy. Microslicer sections were postfixed in $2 \%$ osmium tetroxide for $1 \mathrm{~h}$, stained in block with $2 \%$ uranyl acetate for $20 \mathrm{~min}$, dehydrated, and embedded in Epon 812. Serial ultrathin sections $(90 \mathrm{~nm})$ were prepared with an ultramicrotome (Ultracut UCT; Leica). Each profile of neural and synaptic elements was determined based on the previous description (Peters et al., 1976). Three-dimensional (3D) reconstructed images were constructed and analyzed with an open source software, Reconstruct (Fiala, 2005).

Electrophysiology. Coronal hippocampal slices $(400 \mu \mathrm{m})$ were prepared from DGL $\alpha$-knock-out and wild-type mice at postnatal days 2030, as described previously (Chiu and Castillo, 2008). Mice were decapitated under $\mathrm{CO}_{2}$ anesthesia, and the brain was quickly removed and cooled in an ice-cold, modified external solution containing (in $\mathrm{mM}$ ) 120 choline- $\mathrm{Cl}, 2 \mathrm{KCl}, 8 \mathrm{MgCl}_{2}, 28 \mathrm{NaHCO}_{3}, 1.25 \mathrm{NaH}_{2} \mathrm{PO}_{4}$, and 20 glucose bubbling with $95 \% \mathrm{O}_{2}$ and $5 \% \mathrm{CO}_{2}$. Coronal hippocampal slices
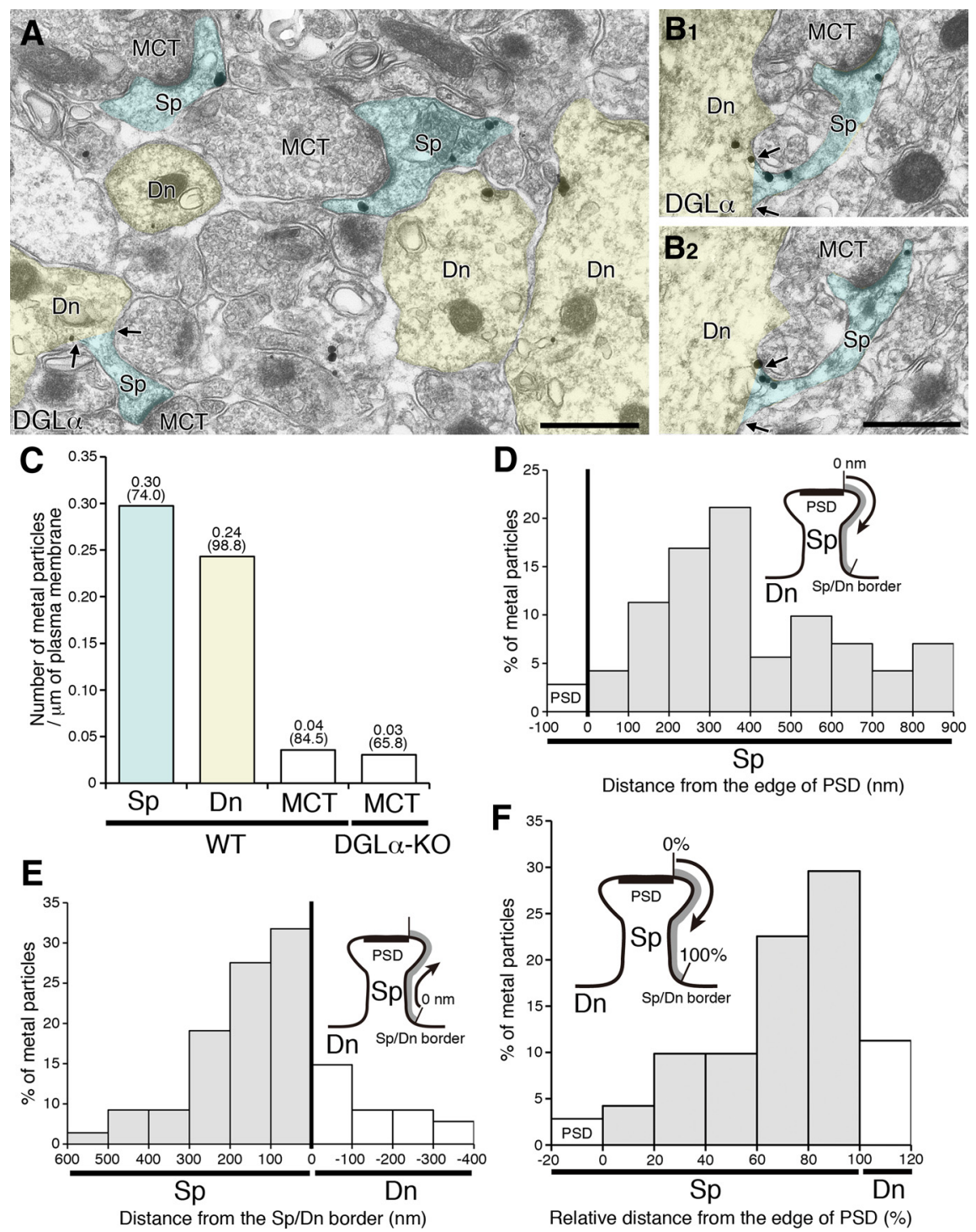

Figure 4. Preferential distribution of DGL $\alpha$ on dendritic spines and shafts of GCs with the highest accumulation in the spine neck. $\boldsymbol{A}, \boldsymbol{B}$, Preembedding silver-enhanced immunogold electron microscopy. Metal particles for DGL $\alpha$ are located on the cell surface of dendritic spines (Sp; blue) and shafts (Dn; yellow) of GCs but not on that of MC terminals (MCT). Note two serial images the mean number of metal particles per $1 \mu \mathrm{m}$ of the plasma membrane in each element of wild-type (WT) and DGL $\alpha$-knock-out (KO) mice. The numbers in and above parentheses on each column indicate the total length of measured plasma membrane or the (in nanometers) from the edge of the PSD (D) or from the spine- dendrite border $(\boldsymbol{E})$ and the normalized distance from the edge of the PSD (0\%) to the spine- dendrite border $(100 \%)(\boldsymbol{F})$. The ordinates indicate the percentage of metal particles falling in each bin. The total number of 71 metal particles was collected from $54 \mathrm{GC}$ spines. Scale bars, $500 \mathrm{~nm}$.

(400 $\mu \mathrm{m})$ were cut with a vibroslicer (VT-1200; Leica), and the slices were immediately placed into a reservoir chamber filled with the standard external solution composed of (in mM) $125 \mathrm{NaCl}, 2.5 \mathrm{KCl}, 2 \mathrm{CaCl}_{2}$, $1 \mathrm{MgSO}_{4}, 1.25 \mathrm{NaH}_{2} \mathrm{PO}_{4}, 26 \mathrm{NaHCO}_{3}$, and 20 glucose, bubbled with $95 \% \mathrm{O}_{2}$ and $5 \% \mathrm{CO}_{2}$, pH 7.4 .

For recording, a single slice was transferred to a submerged recording chamber. The slice was perfused with an external solution at $32^{\circ} \mathrm{C}$ that contained $2.5 \mathrm{mM} \mathrm{CaCl}_{2}$ and $1.3 \mathrm{mM} \mathrm{MgSO}_{4}$ and was supplemented with $100 \mu \mathrm{M}$ picrotoxin $\left(\mathrm{GABA}_{\mathrm{A}}\right.$ receptor antagonist) and $3 \mu \mathrm{M}$ CGP 55845A $\left(\mathrm{GABA}_{\mathrm{B}}\right.$ receptor antagonist). Whole-cell recordings were made from GCs using an upright microscope (BX50WI; Olympus) equipped with an infrared-CCD camera system (Hamamatsu Photonics) (Narushima et al., 2007). Resistance of the patch pipette was $4-5 \mathrm{M} \Omega$ when filled with the intracellular solution containing (in mM) $140 \mathrm{CsCl}, 1$ EGTA, 10 HEPES, $4.6 \mathrm{MgCl}_{2}, 0.1$ $\mathrm{CaCl}_{2}, 4 \mathrm{Na}_{2} \mathrm{ATP}, 0.4 \mathrm{Na}_{2} \mathrm{GTP}$ ( $\mathrm{pH}$ 7.3, adjusted with $\mathrm{CsOH}$ ). The pipette 

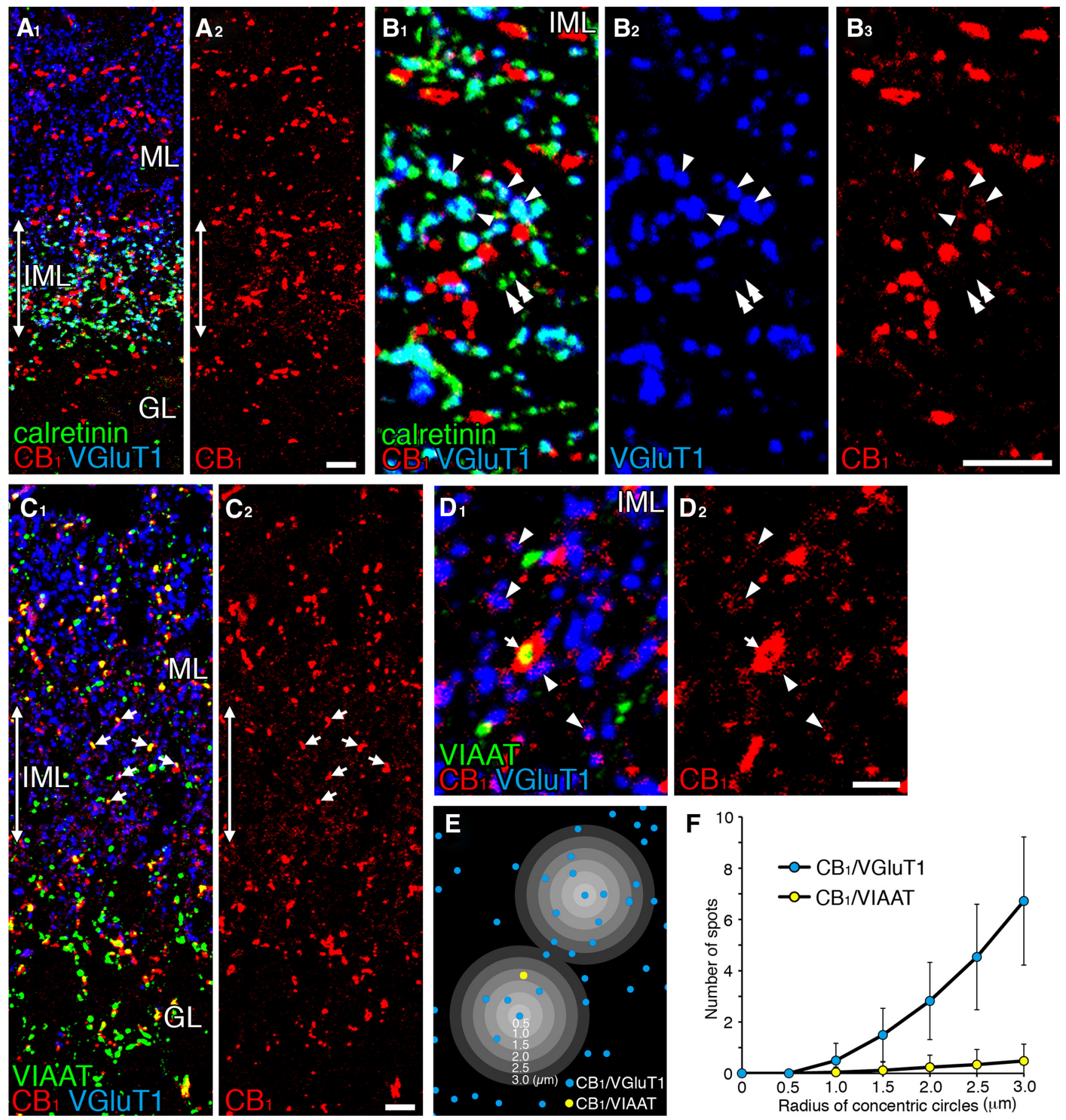

Figure 5. $\quad B_{1}$-expressing $M C$ terminals exist at high densities in the inner molecular layer. $\boldsymbol{A}-\boldsymbol{D}$, Triple immunofluorescence for $\mathrm{CB}_{1}$ (red), VGluT1 (blue), and calretinin ( $\boldsymbol{A}, \boldsymbol{B}$, green) or VIAAT ( $\boldsymbol{C}$, $\boldsymbol{D}$, green) in the dentate gyrus. All images were taken from semithin cryosections (200 $\mathrm{nm}$ in thickness). $\boldsymbol{B}$ and $\boldsymbol{D}$ are high-power images in the inner molecular layer (IML). VGluT1-positive glutamatergic terminals are densely distributed, and most of them are positive for calretinin ( $\boldsymbol{B}$, arrowheads) and express low levels of $C_{1}(\boldsymbol{B}, \boldsymbol{D}$, arrowheads). In contrast, VIAAT-positive inhibitory terminals are sparsely distributed, and some of them express high levels of $C_{1}(C, D$, arrows). Double arrowheads in $B$ indicate calretinin-positive and VGluT1-negative elements; these elements are

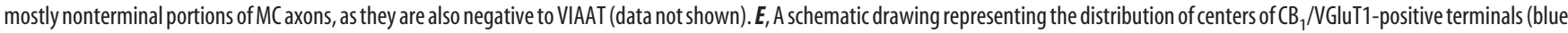
spots) and $\mathrm{B}_{1} /$ VIAAT-positive terminals (yellow spot), as reconstructed from the image in $\boldsymbol{D}$. Concentric circles having the radius of $0.5,1.0,1.5,2.0,2.5$, and $3.0 \mu \mathrm{m}$ are overlaid on two selected blue spots. Note that blue spots included in given concentric circles outnumber yellow spots. $F$, Graph showing the average number of $\mathrm{CB}_{1} / \mathrm{VGluT1}$-positive terminals or $\mathrm{CB}_{1} / \mathrm{VIAAT}_{\mathrm{A}}$-positive terminals in concentric circles with the radius ranging from 0 to $3.0 \mu \mathrm{m} . n=108 \mathrm{CB}_{1} / \mathrm{VGluT1}$-posotive terminals. Error bars indicate SD. ML, Molecular layer; GL, GC layer. Scale bars: $A-C, 5 \mu \mathrm{m} ; \boldsymbol{D}, 2 \mu \mathrm{m}$.

access resistance was compensated by $80 \%$, and the holding potential was $-70 \mathrm{mV}$. To stimulate MC axons, a pair of patch pipettes filled with the external solution was used as a bipolar stimulation electrode. The electrode had a tip separation of $40 \mu \mathrm{m}$ and was placed in the supragranular layer within $40 \mu \mathrm{m}$ from the cell body layer. A previous report (Chiu and Castillo, 2008) showed that medial perforant path inputs, but not MC inputs, were sensitive to group II mGluR agonists. Therefore, we checked whether the evoked EPSCs were suppressed by $1 \mu \mathrm{M}$ DCG-IV (group II mGluR agonist), and only the DCG-IV-insensitive EPSCs were analyzed. EPSCs were evoked at $0.33 \mathrm{~Hz}$ for at least $1 \mathrm{~min}$ to obtain a stable baseline. Then, a depolarizing pulse (from -70 to $0 \mathrm{mV}$, for $3 \mathrm{~s}$ ) was applied to induce DSE. To examine the enhancement of marginal DSE by group I mGluR activation, a series of short 
depolarizing pulses (five pulses of $100 \mathrm{~ms}$ duration, from -70 to $0 \mathrm{mV}$, repeated at $1 \mathrm{~Hz}$ ) was applied to induce marginal DSE with or without the group I mGluR agonist $(R, S)-3,5-$ dihydroxyphenylglycine (DHPG; Tocris Bioscience; $10 \mu \mathrm{M}$, bath applied for at least $10 \mathrm{~min}$ ). Membrane currents were recorded with an EPC9/2 amplifier (HEKA Elektronik). The signals were filtered at $3 \mathrm{kHz}$ and digitized at $20 \mathrm{kHz}$.

\section{Results}

\section{2-AG mediates retrograde suppression} at MC-GC synapse

Because DGL $\alpha$ is the major enzyme responsible for 2-AG production in principal neurons of the striatum, hippocampus, and cerebellum (Gao et al., 2010; Tanimura et al., 2010), we examined whether this was also true at MC-GC synapses. We made whole-cell recordings from GCs (Chiu and Castillo, 2008) and stimulated MC axons with bipolar electrodes in the inner molecular layer $(<40$ $\mu \mathrm{m}$ from the GC layer) at which GCs exclusively receive excitatory MC inputs on their dendritic spines (Shepherd, 2004) (see Fig. 3A-F). In wild-type mice, transient suppression of EPSCs (i.e., DSE) was readily induced by depolarization of GCs (from -70 to $0 \mathrm{mV}$, for $3 \mathrm{~s}$ ) (Fig. $1 A$ ). In contrast, DSE was absent in DGL $\alpha$ knock-out mice (Fig. 1 $A$ ), indicating that DSE at MC-GC synapses is mediated by 2-AG produced by DGL $\alpha$. In wild-type mice, marginal DSE by five short depolarization pulses (from -70 to $0 \mathrm{mV}, 100 \mathrm{~ms}$ duration at $1 \mathrm{~Hz}$ ) was significantly enhanced by bath application of a low dose of group I mGluR agonist DHPG $(10 \mu \mathrm{M})$, which by itself did not cause EPSC suppression (Fig. $1 B$, top). This enhancement of DSE was totally absent in GCs of DGL $\alpha$-knock-out mice (Fig. $1 B$, bottom), indicating that retrograde suppression assisted by group I mGluR activation is also mediated by 2-AG produced by DGL $\alpha$ at MC-GC synapses.

DGL $\alpha$ highly accumulates in the neck portion of GC spines

By fluorescent in situ hybridization using specific riboprobes (supplemental Fig. S2, available at www.jneurosci.org as supplemental material), DGL $\alpha$ mRNA was prominently expressed in GCs and hilar cells of the dentate gyrus (Fig. 2A,B), as reported previously (Katona et al., 2006). Because hilar cells consist of glutamatergic MCs and GABAergic interneurons (Blasco-Ibanez and Freund, 1997), we performed double fluorescent in situ hybridization using glutamatergic neurochemical marker VGluT1 and GABAergic marker GAD67. Most hilar cells highly expressing DGL $\alpha$ mRNA were judged to be MCs, because they coexpressed VGluT1 mRNA (59 of 62 cells expressing high levels of DGL $\alpha$ mRNA) (Fig. 2C, arrows) but not GAD67 mRNA (0 of 44 cells) (Fig. $2 D$, arrows). DGL $\alpha$ mRNA in MCs is likely consistent with depolarization-induced suppression of inhibition (DSI) in MCs (Hofmann et al., 2006). We also found low levels of DGL $\alpha$ mRNA in some interneurons expressing GAD67 mRNA (30 of 44 cells expressing GAD67 mRNA) (Fig. 2D, arrowhead). These results demonstrate that cells highly expressing DGL $\alpha$ mRNA are GCs and MCs in the dentate gyrus.

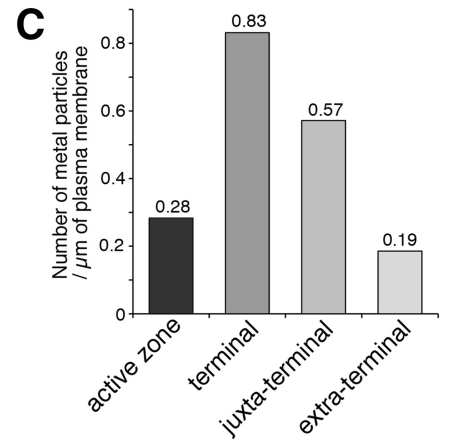

Figure 6. Immunoelectron microscopy showing the distribution of $C_{1}$ in $M C$ axons and its gradient toward the terminal spines and the active zone of $M C$ terminals. $\boldsymbol{B}$. Preembedding silver-enhanced immunogold electron microscopy. Metal particles terminal and juxtaterminal portions, whereas arrowheads indicate the edge of the PSD. Sp, GC spine. C, Bar graph showing the mean labeling density for $\mathrm{CB}_{1}$, i.e., the mean number of metal particles per $1 \mu \mathrm{m}$ of the axolemma. The number on the top of each column indicates the mean labeling density. $n=14$ axons. Scale bar, $200 \mathrm{~nm}$.

To address the major site of $2-\mathrm{AG}$ production at $\mathrm{MC}-\mathrm{GC}$ synapses, we next investigated immunohistochemical localization of DGL $\alpha$ in the molecular layer of the dentate gyrus. We focused on the inner portion of the molecular layer just above the GC layer, because this portion was filled with terminals double labeled for calretinin and VGluT1, which represent MC terminals (Blasco-Ibanez and Freund, 1997; Fujise et al., 1998) (Fig. 3A, B). Compared with the MC terminals, VIAAT-positive inhibitory terminals in the inner molecular layer were apparently few in number (Fig. 3C). On the other hand, calretinin-positive interneuron terminals lacking VGluT1 immunoreactivity were mainly distributed in the hilar region but were very rare in the molecular layer; thus, most calretinin-positive terminals were the MC terminals in the inner molecular layer. Terminals double labeled for VGluT2 and VIAAT, which represent afferents from the supramammillary nucleus (Soussi et al., 2010), were distributed in the upper portion of the GC layer, but not in the MC-recipient molecular layer (Fig. 3C,D). VAChT-positive cholinergic terminals were also sparse in the MC-recipient molecular layer (Fig. $3 E, F$ ). These results suggest that the majority of synapses in the inner molecular layer is formed by MC terminals.

In the inner molecular layer, DGL $\alpha$ showed a dense punctate pattern of immunofluorescence (Fig. 3G). These puncta were preferentially distributed along dendritic branches labeled for MAP2 (Fig. 3H) and apposed to nerve terminals labeled for synaptophysin (Fig. 3I, arrowheads), suggesting postsynaptic localization in spines, dendrites, or both. To confirm the spine 

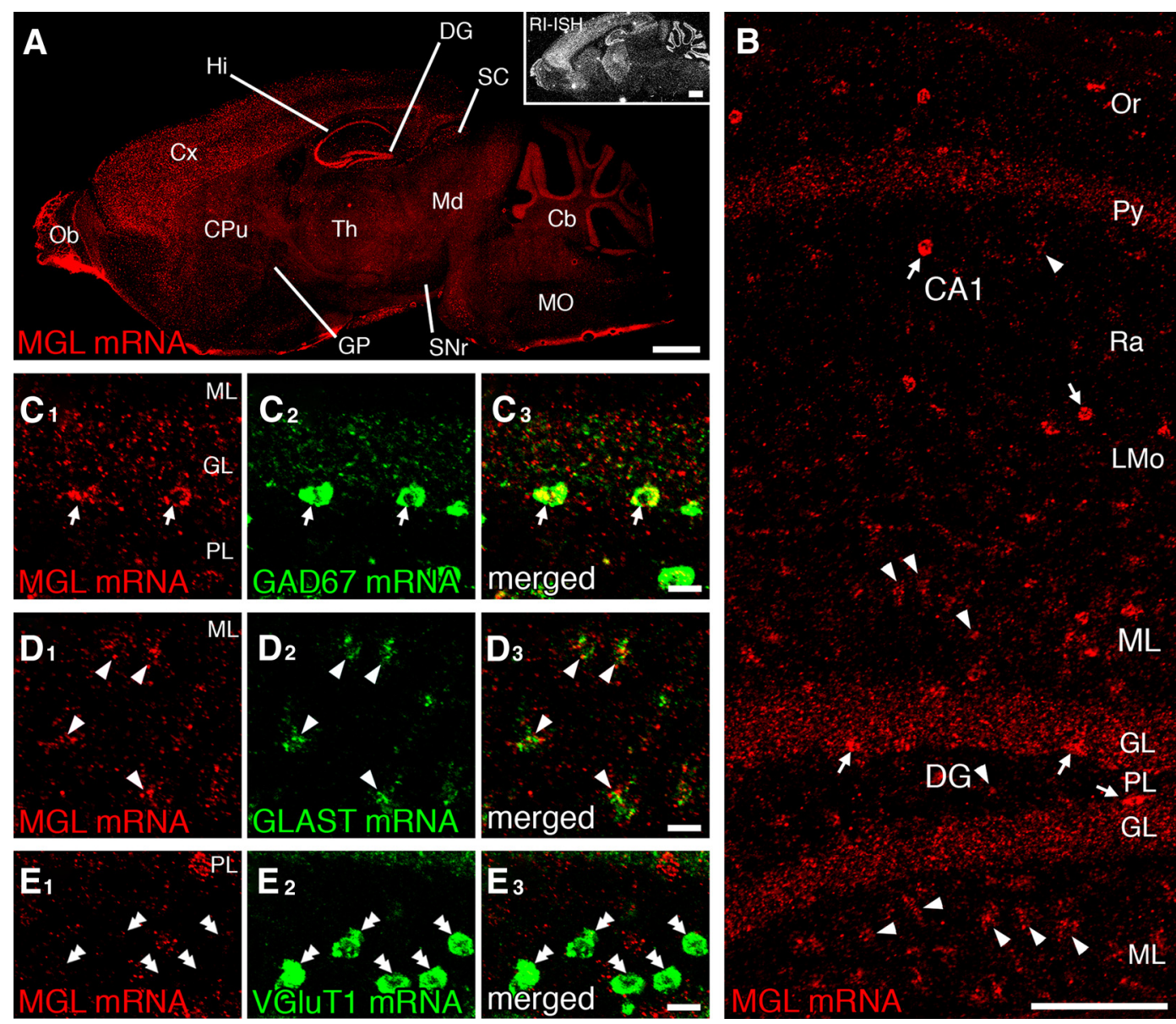

Figure 7. In situ hybridization showing distinct cellular expression of MGL mRNA in the dentate gyrus. A, Fluorescent in situ hybridization (FISH) and isotopic in situ hybridization (RI-ISH; inset) for MGL mRNA in parasagittal brain sections. B, FISH for MGL mRNA in the hippocampus formation. Principal neurons are labeled at moderate levels in the dentate GC layer (GL) and hippocampal pyramidal cell layer (Py). Note that medium-sized (arrows) or small (arrowheads) cells express MGL mRNA at high or low levels, respectively. C-E, Double FISH for MGL mRNA (red) with GAD67 (C, green), GLAST ( $\boldsymbol{D}$, green), or VGluT1 ( $\boldsymbol{E}$, green) mRNA. Note that MGL mRNA is expressed at high levels in inhibitory interneurons labeled for GAD67 mRNA (C, arrows) and at low levels in astrocytes labeled for GLAST mRNA ( $\boldsymbol{D}$, arrowheads). In contrast, MGL mRNA is negative in MCs identified by VGluT1 mRNA labeling ( $\boldsymbol{E}$, double arrowheads). Cb, Cerebellum; $C$ Pu, caudate-putamen; $(\mathrm{X}$, neocortex; DG, dentate gyrus; GP, globus pallidus; Hi, hippocampus; Md, midbrain; MO, medulla oblongata; Ob, olfactory bulb; SNr, substantia nigra pars reticulata; SC, superior colliculus; Th, thalamus; CA1, CA1 subregion of the hippocampus; Or, stratum oriens; Ra, stratum radiatum; LMo, lacunosum moleculare; ML, molecular layer; PL, polymorphic layer. Scale bars: $\boldsymbol{A}, 1 \mathrm{~mm} ; \boldsymbol{B}, 200$ $\mu \mathrm{m} ; C-E, 20 \mu \mathrm{m}$.

localization, triple fluorescence was conducted for mGluR5, a major group I mGluR in the telencephalon, and F-actin, both being enriched in the head portion of spines (Lujan et al., 1996; Capani et al., 2001). Indeed, mGluR5 and F-actin were considerably overlapped with each other (Fig. $3 J_{1}, J_{3}$, arrows). Unexpectedly, DGL $\alpha$ was not overlapped, but rather positioned side by side, with mGluR5 (data not shown) and with F-actin (Fig. 3J ${ }_{4}$ ). To assess the different distribution of two fluorescent signals quantitatively, we calculated the mean correlation coefficient of F-actin with mGluR5, DGL $\alpha$, or MAP2, the latter used as a marker molecule distributed in dendritic shafts but not in dendritic spines. The mean correlation coefficient of F-actin and DGL $\alpha$ was lower value than that of F-actin and mGluR5 but higher than that of F-actin and MAP2 (Fig. 3K), suggesting the accumulation of DGL $\alpha$ between the dendritic shaft and spine head.

To address precise localization of $\operatorname{DGL} \alpha$, we applied the preembedding silver-intensified immunogold electron microscopy (Fig. 4). Most metal particles were distributed on the plasma membrane of dendritic spines and shafts with a few attached to the endoplasmic reticulum (Fig. 4A,B). By quantification, the mean density of immunogold particles on the plasma membrane was similarly high in spines and shafts of GC dendrites, whereas that on MC terminals was at around the background level, as determined using DGL $\alpha$-knock-out mice (Fig. 4C). In labeled spines, metal particles were found more often around the neck portion than the head portion (Fig. $4 \mathrm{~B}$ ). Intraspine distribution was evaluated by plotting the distribution of metal particles as a function of the distance from the edge of the postsynaptic density (PSD) (Fig. 4D) or from the spine-dendrite boarder (Fig. 4E) ( $n=54$ GC spines). The peak distribution was apart from the edge of the PSD (Fig. 4D) and observed near the spine-dendrite boarder (Fig. $4 E$ ). When the distribution of metal particles was plotted relative to the edge of the PSD $(0 \%)$ and the spine-dendrite border (100\%), the peak distribution was at the $80-100 \%$ bin, i.e., the base of the spine neck, and decreased progressively toward the edge of the PSD (Fig. 4F). These results suggest that 2-AG is synthesized in, and released from, dendritic spines and shafts, particularly at the spine neck portion.

\section{$\mathrm{CB}_{1}$ accumulates in the terminal portion of $\mathrm{MC}$ axons}

In the dentate gyrus, $\mathrm{CB}_{1}$ is expressed weakly in $\mathrm{MC}$ terminals and intensely in CCK-positive interneuron terminals (Katona et al., 1999, 2006; Kawamura et al., 2006; Monory et al., 2006). To 

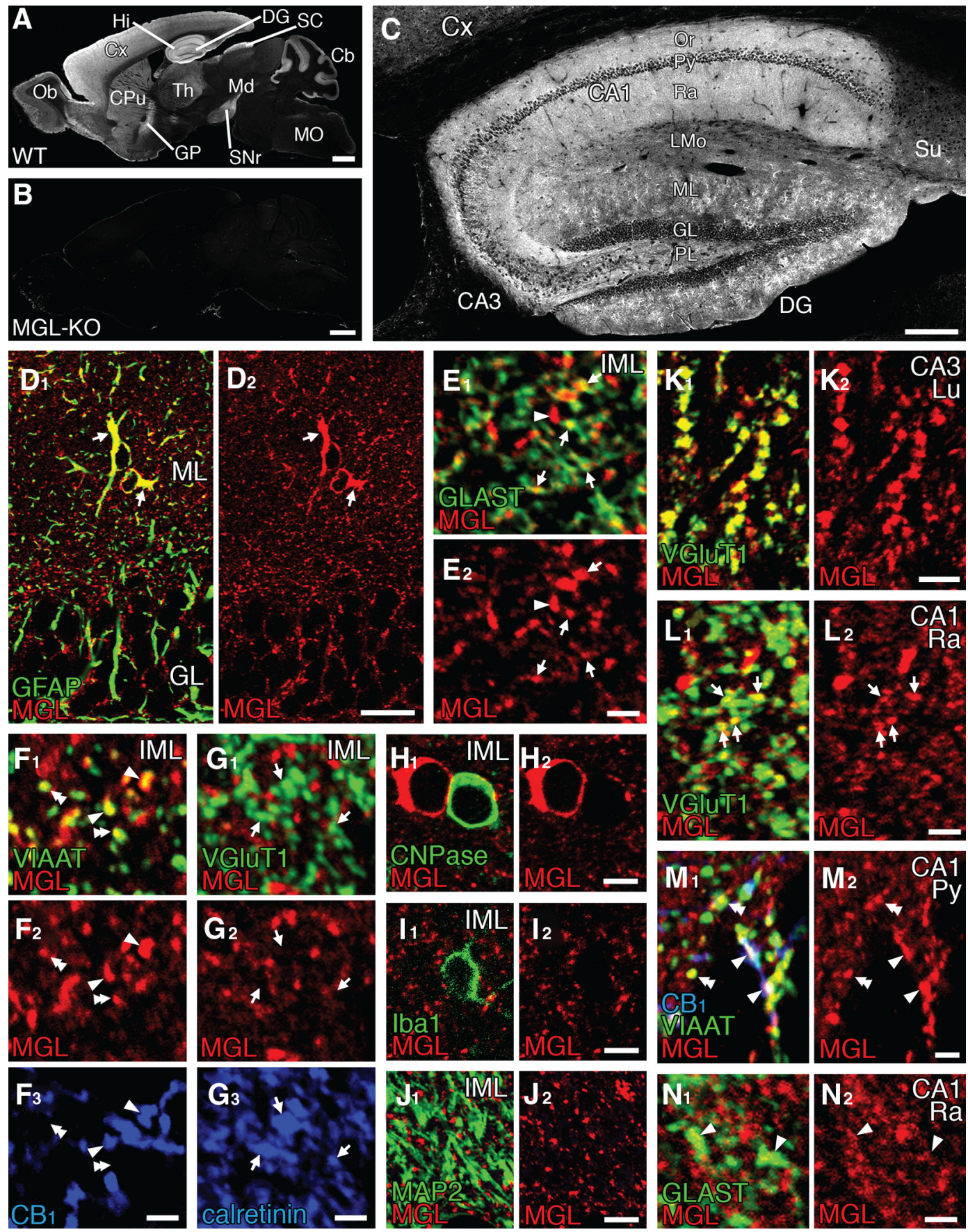

Figure 8. MGL is expressed in astrocytes and some inhibitory terminals in the dentate gyrus and hippocampus. $A-C$, Immunofluorescence for MGL in parasagittal brain sections of wild-type (WT $\boldsymbol{A}, \boldsymbol{C}$ ) and MGL-knock-out (KO; $\boldsymbol{B})$ mice. $\boldsymbol{C}$, An enlarged view of the hippocampus formation. $\boldsymbol{D}, \boldsymbol{E}$, Double immunofluorescence for MGL (red) and astrocytic marker GFAP ( $\boldsymbol{D}$, green) or GLAST (E, green) in the inner molecular layer (IML) of the dentate gyrus. Note the overlap of MGL with GFAP in perikarya and shaft processes of astrocytes ( $\boldsymbol{D}$, arrows) and with GLAST in their peripheral processes ( $\boldsymbol{E}$, arrows). The arrowhead in $\boldsymbol{E}$ indicates intense MGL in GLAST-immunonegative elements (putative inhibitory terminals). $\boldsymbol{F}$, Triple immunofluorescence for MGL (red), VIAAT (F1, green), and CB ( $\boldsymbol{F 3}$, blue) in the IML. Note that intense MGL is found in many VIAAT-positive inhibitory terminals, which include both $\mathrm{CB}_{1}$-positive (arrowheads) and $\mathrm{CB}_{1}$-negative (double arrowheads) terminals. $\mathbf{G}$, Triple immunofluorescence for MGL (red), VGluT1 (G1, green), and calretinin (G3, blue) in the IML. Note that there is no MGL immunoreactivity in MC terminals colabeled for VGluT1 and calretinin (arrows). $\boldsymbol{H}-\boldsymbol{J}$, Double immunofluorescence for MGL (red) with CNPase $(\boldsymbol{H}$, green), lba1 ( $\boldsymbol{I}$, green), or MAP2 $(\boldsymbol{J}$, green). Note that there is no MGL labeling in CNPase-positive oligodendrocytes, Iba1-positive microglia, or MAP2-positive neuronal dendrites. $\boldsymbol{K}$, $\boldsymbol{L}$, Double immunofluorescence for MGL (red) and VGluT1 (green) in the hippocampal CA3 (K) and CA1 (L). $\boldsymbol{M}$, Triple immunofluorescence for MGL (red), VIAAT (green), and CB (blue) in the hippocampal CA1. N, Double immunofluorescence for MGL and GLAST in the hippocampal CA1. In the CA3, intense immunoreactivity is detected in VGluT1-labeled mossy fiber terminals $(\boldsymbol{K})$. In the CA1, MGL immunoreactivity is detected in VGluT1-labeled excitatory terminals of Schaffer collaterals ( $\mathbf{L}$, arrows), VIAAT-labeled inhibitory terminals including both $\mathrm{CB}_{1}$-positive $\left(\boldsymbol{M}\right.$, arrowheads) and $\mathrm{CB}_{1}$-negative $(\boldsymbol{M}$, double arrowheads) ones, and GLAST-labeled astrocytes $(\boldsymbol{N}$, arrowheads). $\mathrm{Cb}$, $\mathrm{Cerebellum}$; $\mathrm{CPu}$, caudateputamen; $\mathrm{Cx}$, neocortex; DG, dentate gyrus; GP, globus pallidus; Hi, hippocampus; Md, midbrain; M0, medulla oblongata; Ob, olfactory bulb; SNr, substantia nigra pars reticulata; $\mathrm{SC}$, superior colliculus; Th, thalamus; Su, subiculum; Or, stratum oriens; Py, pyramidal cell layer; Ra, stratum radiatum; LMo, lacunosum moleculare; ML, molecular layer; GL, GC layer; PL, polymorphic layer; Lu, stratum lucidum. Scale bars: $A, B, 1 \mathrm{~mm} ; C, 200 \mu \mathrm{m} ; \mathbf{D}, 20 \mu \mathrm{m} ; \boldsymbol{E}-\mathbf{G}, \mathbf{L}-\mathbf{N}, 2 \mu \mathrm{m} ; \boldsymbol{H}-\boldsymbol{K}, 5 \mu \mathrm{m}$. 


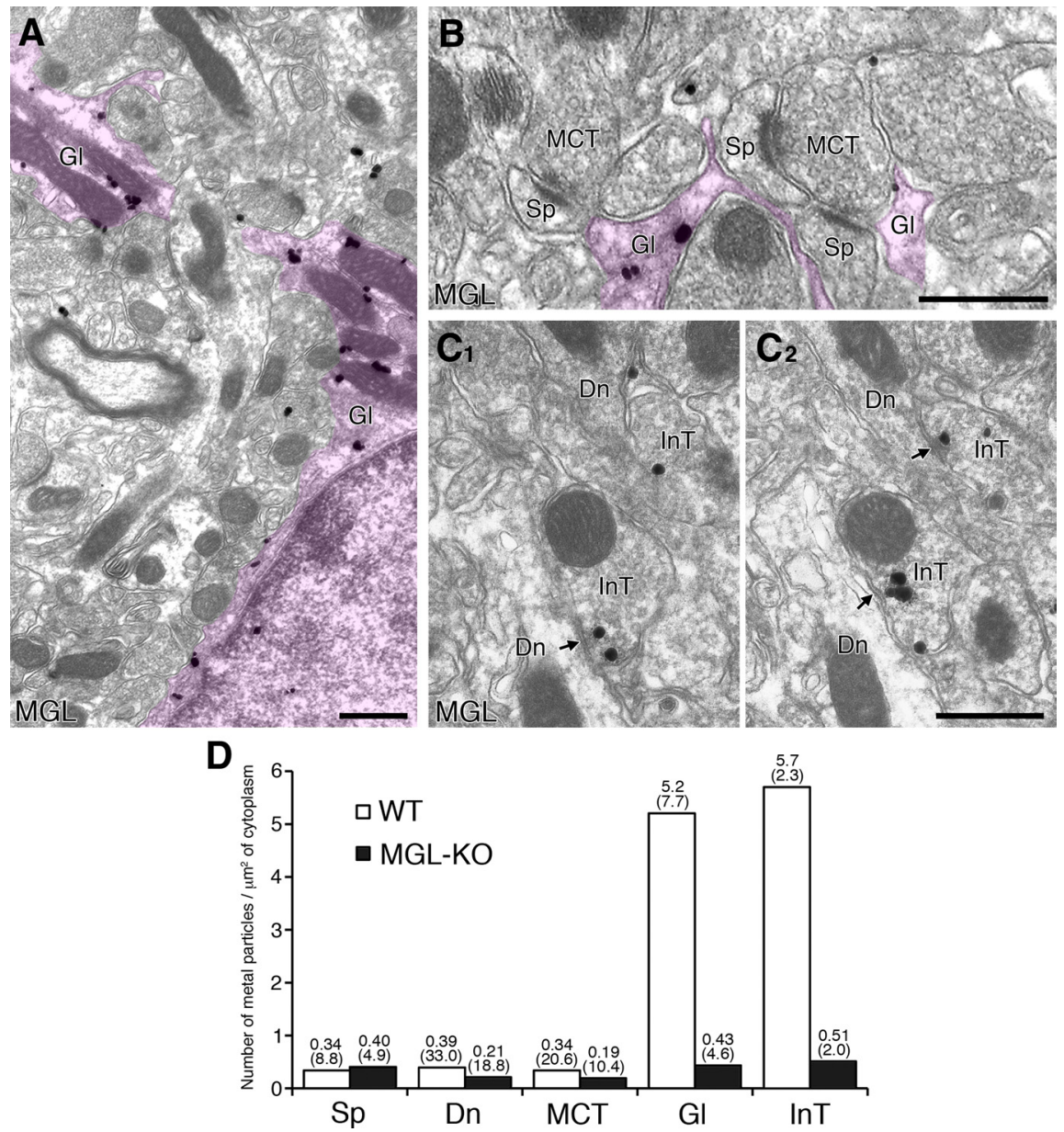

Figure 9. MGL is selectively localized in glial elements and inhibitory terminals in the inner molecular layer of the dentate gyrus. $\boldsymbol{A}, \boldsymbol{B}$, Preembedding silver-enhanced immunogold electron microscopy. Metal particles are distributed inside perikarya and lamellate processes of glial cells (Gl; purple) but not in MC terminals (MCT) or GC spines (Sp). C, Two serial images showing consistent MGL labeling in inhibitory terminals (InT) forming symmetrical synapses (arrows) with dendritic shafts (Dn). D, Bar graph showing the number of metal particles for MGL per $1 \mu \mathrm{m}^{2}$ of the cytoplasmic area in each subcellular element of wild-type (WT; open bars) and MGL-knock-out (KO; filled bars) mice. The numbers in and above parentheses on the top of each column indicate the total area analyzed and the mean labeling density, respectively. Scale bars, $500 \mathrm{~nm}$.

quantitatively evaluate $\mathrm{CB}_{1}$ expression and distribution in $\mathrm{MC}$ axons, we applied triple immunofluorescence to semithin cryosections (200 nm in thickness) to obtain high-resolution images (Fig. 5). Indeed, weak immunoreactivity for $\mathrm{CB}_{1}$ was detected in MC terminals colabeled for VGluT1 and calretinin (Fig. 5A, $B$, arrowheads). Because VGluT1 was exclusively overlapped with calretinin (90\%, 109 of 121 VGluT1-positive terminals) (Figs. $3 B, 5 A, B)$ and also because VGluT1-negative nonterminal axons of MCs were stained for calretinin (Fig. $5 B$, double arrowheads), VGluT1-positive terminals thus mostly represent MC terminals in the inner molecular layer. Then, using VGluT1 and VIAAT, we quantitatively examined $\mathrm{CB}_{1}$ expression in terminals of MCs or interneurons, respectively (Fig. $5 C-F$ ). $\mathrm{CB}_{1}$ was detected, although low in intensity, in most of the VGluT1-positive terminals $(72 \%, 188$ of 260 terminals) (Fig. 5D, arrowheads). On the other hand, $30 \%$ of VIAAT-positive terminals (127 of 420 terminals) exhibited intense signals for $\mathrm{CB}_{1}$ (Fig. 5C,D, arrows).

Obviously, VGluT1-positive terminals expressing $\mathrm{CB}_{1}$ were outnumbered by VIAAT-positive terminals expressing $\mathrm{CB}_{1}$ in the inner molecular layer (Fig. 5C,D), suggesting that $\mathrm{MC}$ terminals are positioned far more close to other MC terminals than to interneuron terminals. This was substantiated by plotting the centers of VGluT1-positive/ $\mathrm{CB}_{1}$-positive terminals and VIAAT-positive/ $\mathrm{CB}_{1}$-positive terminals as blue or yellow spots, respectively (Fig. $5 E$ ), and by counting their numbers contained in $0.5-$ to $3.0-\mu \mathrm{m}$ radius circles around a given $\mathrm{MC}$ terminal (Fig. 5F). The average number of blue spots increased steeply as a function of the radius: $1.6 \pm 1.1$ (mean $\pm \mathrm{SD}$ ) and $6.7 \pm 2.5$ blue spots in 1.5- and 3.0- $\mu \mathrm{m}$-radius circles, respectively. However, the average number of yellow spots remained as low as $0.2 \pm 0.4$ and $0.6 \pm 0.7$ in 1.5 - and 3.0- $\mu \mathrm{m}$-radius circles, respectively.

Detailed distribution of $\mathrm{CB}_{1}$ in $\mathrm{MC}$ axons was assessed by the preembedding silver-intensified immunogold electron microscopy (Fig. 6). Because of the diverse shape and size of MC terminals, we defined the terminal portion as synaptic vesicleaccumulating regions and the juxtaterminal and extraterminal portions as $0-0.5$ and $>0.5 \mu \mathrm{m}$ from the edge of the terminal portion (Fig. 6A). By collecting immunolabeled axon profiles containing all three portions ( $n=14$ axons), metal particles for $\mathrm{CB}_{1}$ were mainly localized on the plasma membrane of $\mathrm{MC}$ axons, and the density of plasma membrane labeling was in the order of terminal $>$ juxtaterminal $>$ extraterminal portions (Fig. $6 B, C$ ). Labeling density in the active zone, which was defined as the presynaptic membrane opposite to the PSD, was as low as that in the extraterminal portion (Fig. 6C). To assess the probability of positive $\mathrm{CB}_{1}$ labeling in $\mathrm{MC}$ terminals at the electron microscopic level, we examined three serial sections for each terminal, and found one or more metal particles in $83 \%$ of MC terminals examined ( $n=66$ terminals), almost consistent with the result by immunofluorescence microscopy (72\%). Therefore, $\mathrm{CB}_{1}$ is expressed in most $\mathrm{MC}$ terminals and accumulates toward the terminal portion of $\mathrm{MC}$ axons.

\section{MGL is lacking in MC-GC synapses}

As a major degrading enzyme, MGL restricts the spread of 2-AG both spatially and temporally (Hashimotodani et al., 2007a; Pan et al., 2009). We next examined cellular expression and subcellular distribution of MGL. As reported previously (Dinh et al., 2002), MGL mRNA was widely expressed in the brain with high levels in the GC and pyramidal cell layers of the hippocampal formation (Fig. 7A). In addition to the principal cell layers, we found two distinct patterns of cellular labeling in the neuropil, i.e., intense labeling in large oval or polygonal cells (Fig. $7 B$, arrows) and weak labeling in small irregular cells (Fig. $7 B$, arrowheads). In the dentate gyrus, all cells with the former labeling were interneurons expressing GAD67 mRNA (48 of 48 cells expressing MGL mRNA) (Fig. 7C, arrows), whereas cells with the latter labeling were astrocytes expressing GLAST mRNA, an astrocyte-specific glutamate/aspartate transporter (110 of 122 cells) (Fig. 7D, arrowheads). However, MGL mRNA was not detected in almost all MCs 
expressing VGluT1 mRNA in the hilus (1 of 47 cells expressing VGluT1 mRNA) (Fig. $7 E$, double arrowheads). Thus, MGL mRNA is expressed in various cells in the dentate gyrus, except for MCs.

Immunohistochemical distribution and localization were examined using the MGL antibody, whose specificity was verified by blank immunoblot (supplemental Fig. S1F, available at www.jneurosci.org as supplemental material) and blank immunohistochemical labeling (Fig. 8A,B) in MGL-knock-out brains. In the dentate gyrus, the glia-like immunostaining pattern was evident (Fig. 8C). By double immunofluorescence with astrocyte markers, MGL was overlapped with GFAP in perikarya and shaft processes of astrocytes (Fig. $8 D$, arrows) and with GLAST in their peripheral processes (Fig. $8 E$, arrows). There was also a punctate pattern of immunolabeling, which was negative for GLAST (Fig. 8E, arrowheads). These puncta were inhibitory terminals expressing VIAAT (Fig. $8 F$ ). MGL was detected in both $\mathrm{CB}_{1}$-positive/VIAAT-positive terminals ( 33 of 47 terminals) (Fig. $8 F$, single arrowheads) and $\mathrm{CB}_{1}$-negative/VIAATpositive terminals (60 of 73 terminals) (Fig. $8 F$, double arrowheads), but not in MC terminals labeled for VGluT1 and calretinin (Fig. 8G, arrows). No MGL immunoreactivity was detected in oligodendrocytes labeled for CNPase (Fig. $8 \mathrm{H}$ ), microglia labeled for Ibal (Fig. $8 I$ ), and neuronal dendrites labeled for MAP2 (Fig. 8J). Consistent with MGL mRNA expression in GCs and pyramidal cells, MGL labeling was found in VGluT1-labeled mossy fiber terminals in the CA3 (Fig. $8 \mathrm{~K}$ ) or VGluT1-labeled Schaffer collateral terminals in the CA1 (Fig. $8 \mathrm{~L}$, arrows). In the CA1, MGL was detected in both $\mathrm{CB}_{1}$ positive/VIAAT-positive (Fig. $8 \mathrm{M}$, arrowheads) and $\mathrm{CB}_{1}$-negative/ VIAAT-positive (Fig. $8 M$, double arrowheads) terminals and also in GLAST-expressing astrocytic processes (Fig. $8 \mathrm{~N}$, arrowheads). Thus, MGL is expressed in various nerve terminals and astrocytes, except for MC terminals and some interneuron terminals.

This was confirmed by immunoelectron microscopy in the inner molecular layer (Fig. 9). Metal particles for MGL were widely distributed in the cytoplasm of astrocytes from perikarya to peripheral processes enwrapping MC-GC synapses (Fig. $9 A, B$, colored area). Occasionally, metal particles appeared to be associated with membranous structures, such as the cell membrane and mitochondria. Cytoplasmic and membraneassociated distribution of MGL is consistent with previous studies (Dinh et al., 2002: Blankman et al., 2007). At inhibitory synapses made onto dendritic shafts, metal particles were selective to presynaptic terminals (Fig. 9C). We measured the density of MGL labeling in each element (Fig. 9D). Labeling densities in glial processes and inhibitory terminals were similarly high in wild-type mice and, by far, exceeded those in MGL-knock-out mice. In contrast, labeling densities in MC

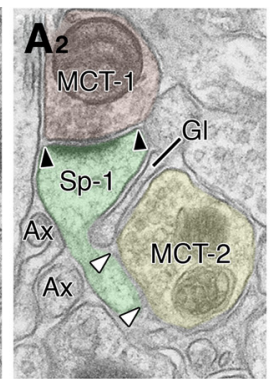

B
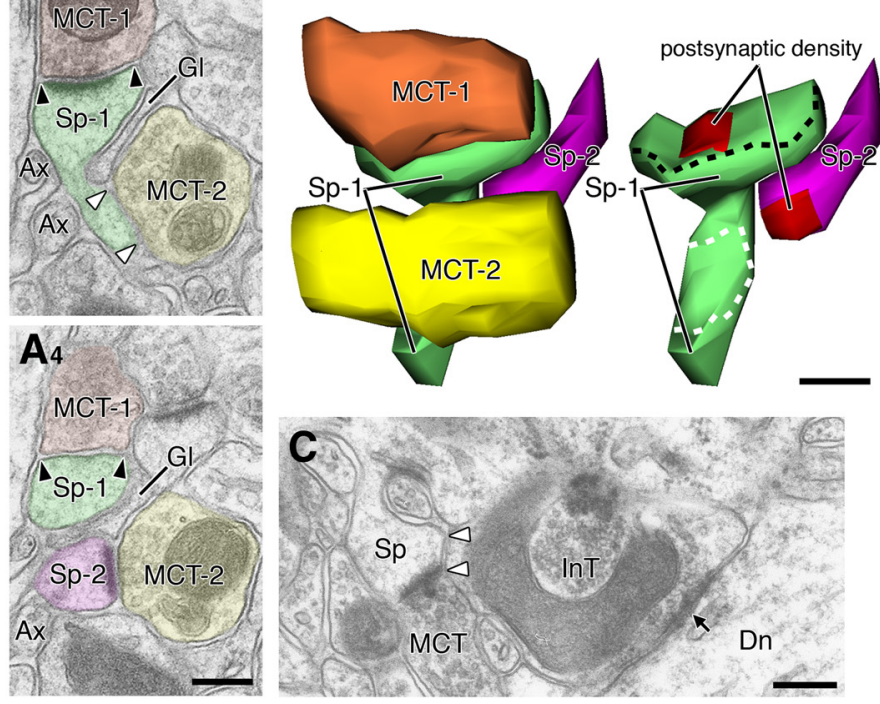

E

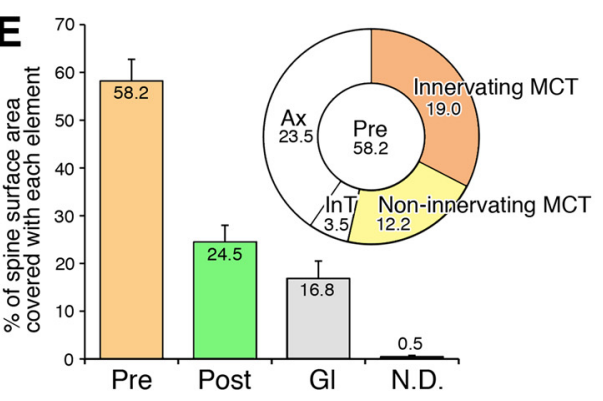

Figure 10. Serial electron microscopic analysis for subcellular elements contacting to $\mathrm{GC}$ spines. $\boldsymbol{A}, \boldsymbol{B}$, Four serial electron with presynaptic (Pre), postsynaptic (Post), and glial elements. The numbers and error bars indicate the mean percentage and SEM. N.D., Elements that could not be identified. A circular graph shows the percentage of GC spine surface area covered with respective presynaptic elements, i.e., innervating MC terminals, noninnervating MC terminals, InT, and Ax. Scale bars, $200 \mathrm{~nm}$.

terminals, GC spines, and GC dendrites in wild-type mice were as low as those in MGL-knock-out mice. Therefore, astrocytes and some inhibitory terminals are the cellular elements expressing MGL in the inner molecular layer.

GC spine is contacted nonsynaptically by other MC terminals making synapses with other nearby GC spines

The aforementioned findings suggest that once 2-AG is liberated, retrograde suppression of glutamate release is readily induced at activated MC-GC synapses and also spreads to other MC-GC synapses in the neighborhood. In this respect, we finally investigated to what extents given GC spines were surrounded with respective neural elements by $3 \mathrm{D}$ reconstruction of $57 \mathrm{GC}$ spines (Fig. 10). In all spines analyzed, each formed asymmetrical synapses with a single $\mathrm{MC}$ terminal on the spine head (Sp-1 with MCT-1 and Sp-2 with MCT-2) (Fig. 10 A,B). Moreover, the head and neck portions of GC spines were nonsynaptically contacted by other MC terminals making synaptic contacts with other GC spines in the neighbor (Fig. 10A, B, between Sp-1 and MCT-2). As shown in Figure 10D, 80.7\% of GC spines had such nonsyn- 
aptic contacts with one to three MC terminals. GC spines were also contacted nonsynaptically by inhibitory terminals, nonterminal axons of undefined origins, dendritic spines and shafts, and glial processes (Fig. 10A,C).

From 15 reconstructed GC spines, we calculated the coverage ratio; $58.2 \pm 4.5 \%$ (mean \pm SEM), $24.5 \pm 3.5 \%$, and $16.8 \pm 3.7 \%$ of the total spine surface were covered with presynaptic, postsynaptic, and glial elements, respectively (Fig. 10 E, bar graphs). Presynaptic elements contacting GC spines were MC terminals innervating the spine (19.0 $\pm 2.2 \%$ of the total spine surface), noninnervating MC terminals (12.2 $\pm 3.5 \%)$, inhibitory terminals $(3.5 \pm 2.3 \%)$, and nonterminal axons $(23.5 \pm 3.8 \%)$ (Fig. $10 E$, circular graph). Thus, GC spines are commonly contacted by noninnervating MC terminals, whereas glial elements only cover one-sixth of the total spine surface.

\section{Discussion}

2-AG synthesized by DGL $\alpha$ plays a major role in eCB-mediated retrograde signaling at various synapses in the brain (Gao et al., 2010; Tanimura et al., 2010). However, it has been controversial as to the role of 2-AG or DGL in eCB-mediated retrograde suppression at $\mathrm{MC}-\mathrm{GC}$ synapses (Chiu and Castillo, 2008). In the present study, we have demonstrated that DSE and its enhancement by group I mGluR activation were abolished in DGL $\alpha$ knock-out mice (Fig. 1), indicating that 2-AG produced by DGL $\alpha$ mediates these forms of short-term plasticity. Furthermore, we have disclosed the arrangement of molecules for 2-AGmediated retrograde signaling at $\mathrm{MC}-\mathrm{GC}$ synapses, and the main findings are illustrated in Figure 11.

\section{Molecular-anatomical configuration for 2-AG-mediated retrograde signaling}

Katona et al. (2006) first reported the expression of DGL $\alpha$ in GC spines. In the present study, we confirmed this result and also revealed its distribution in dendritic spines and shafts with the highest density at the spine neck portion (Fig. 4). The spine neck accumulation of DGL $\alpha$ matches with its close but nonoverlapping patterns with F-actin and mGluR5 (Fig. $3 H, I$ ). Such spine neck accumulation is also found in cerebellar Purkinje cells (Yoshida et al., 2006). As the spine head is the site for the formation of glutamatergic synapses and for the accumulation of ionotropic and mGluRs in principal neurons (Harris and Kater, 1994), activation of these glutamate receptors will trigger DGL $\alpha$-mediated 2-AG synthesis at around the neck portion of activated GC spines. This leads to 2-AG-mediated retrograde suppression of glutamate release, as we have shown electrophysiologically (Fig. $1)$. When synaptic activation is further enhanced by repetitive stimuli, the site of 2-AG synthesis will extend to dendritic shafts, because dendritic shafts of principal neurons are also provided with a complete set of molecular machineries for 2-AG synthesis, i.e., mGluR5, $\mathrm{G} \alpha_{\mathrm{q} / 11}$, phospholipase C $\beta 1$, and DGL $\alpha$ (Tanaka et al., 2000; Fukaya et al., 2008; Yamasaki et al., 2010). Considering that dendritic shafts of principal neurons are the major site for inhibitory synapse formation, 2-AG synthesis at dendritic shafts will favor DSI. Therefore, molecular machinery for 2-AG synthesis is well orchestrated in dendritic shafts and spines of GCs.

On the other hand, $\mathrm{CB}_{1}$ expression in most $\mathrm{MC}$ terminals was revealed by immunofluorescence and immunogold electron microscopy (Figs. 5, 6). This is consistent with a previous study showing intense expression of $\mathrm{CB}_{1}$ mRNA in MCs and high degrees of coexpression of $\mathrm{CB}_{1}$ and VGluT1 in the MC-recipient molecular layer (Monory et al., 2006). We also revealed that $\mathrm{CB}_{1}$ was distributed in MC axons with a gradient toward the terminal

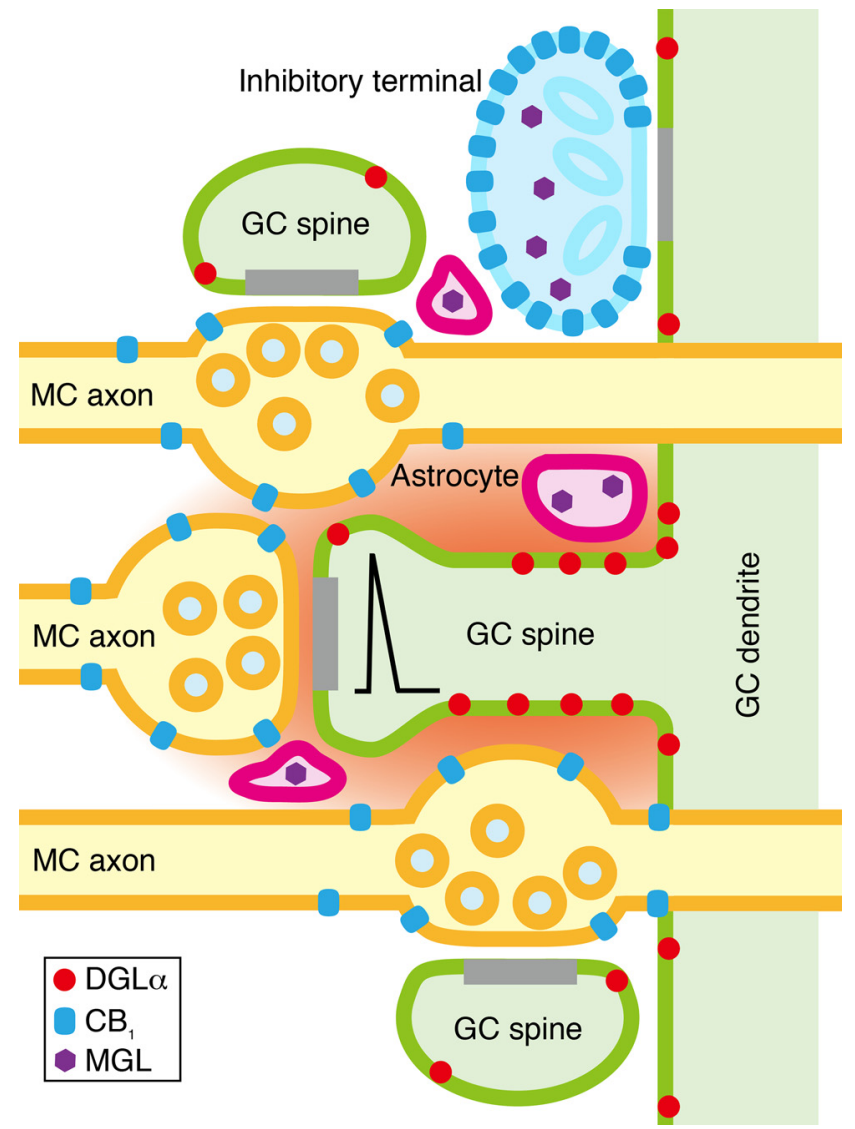

Figure 11. The molecular-anatomical configuration of 2-AG-mediated retrograde signaling and cross talk at $M C-G C$ synapses in the dentate gyrus. The molecular-anatomical configuration of 2-AG-mediated signaling at MC-GC synapses includes (1) wide distribution of DGL $\alpha$ in dendritic spines and shafts of $G(s$ with the highest accumulation at the spine neck portion, (2) accumulation of $\mathrm{CB}_{1}$ in the terminal portion of $\mathrm{MC}$ axons, (3) spatial proximity among $\mathrm{MC}-\mathrm{GC}$ synapses that causes frequent contact of GC spines to other $M C$ terminals making synaptic contacts with other $\mathrm{GC}$ spines, and (4) incomplete surrounding of $\mathrm{GC}$ spines by MGL-expressing elements (astrocytes and some inhibitory terminals). These characteristics provide the framework fundamental to 2-AG-mediated retrograde signaling and also suggest 2-AG-mediated intersynaptic cross talk among local MC-GC synapses. This molecular-anatomical configuration will be important to adjust network activity in the dentate gyrus after enhanced excitability.

portion. The spine neck accumulation of DGL $\alpha$ in GC spines and the terminal accumulation of $\mathrm{CB}_{1}$ in $\mathrm{MC}$ axons will be an important molecular-anatomical basis for the organization and promotion of 2-AG-mediated retrograde suppression of this excitatory recurrent synapse (Fig. 11).

\section{Molecular-anatomical configuration for 2-AG-mediated local cross talk}

In addition to the above arrangement of DGL $\alpha$ and $\mathrm{CB}_{1}$, the following facts will also predict 2-AG-mediated cross talk among local synapses in the MC-recipient molecular layer of the dentate gyrus.

Although molecular mechanisms for 2-AG reuptake across the cell membrane remain unclear (Hermann et al., 2006), MGL is established as the major enzyme involved in the subsequent degradation and termination of 2-AG-mediated retrograde signaling (Hashimotodani et al., 2007a; Pan et al., 2009; Schlosburg et al., 2010). In the inner molecular layer, we detected MGL in astrocytes and some inhibitory terminals (including both $\mathrm{CB}_{1}$ expressing and nonexpressing terminals), but not in MC terminals 
or GC spines (Figs. 8, 9). The specificity of immunohistochemical labeling for MGL was validated by blank immunohistochemistry in MGL-knock-out mice. The lack of MGL immunolabeling in MC terminals is also consistent with the lack of detectable MGL mRNA in MCs (Fig. 7). Furthermore, MGL expression in astrocytes is consistent with a previous study using cultured astrocytes (Walter et al., 2004). Therefore, in the MC-recipient molecular layer, MGLmediated degradation of 2-AG should be conducted by astrocytes and some inhibitory terminals to restrict the spatial and temporal extents of 2-AG-mediated retrograde suppression in local areas. However, astrocytes and inhibitory terminals only covered 16.8 and $3.5 \%$ of the total surface of GC spines, respectively (Fig. 10). This suggests that, within short-range distances, 2-AG released from a given GC spine will readily escape from enzymatic degradation by MGL and can reach and bind its neighboring structures expressing $\mathrm{CB}_{1}$, most likely other MC-GC synapses. In the hippocampal CA1 and CA3, MGL is expressed not only in inhibitory terminals but also in excitatory terminals innervating pyramidal cells (Gulyas et al., 2004). In the present study, we confirmed this and also clarified MGL expression in astrocytes of the CA1 region (Fig. $8 \mathrm{~K}-\mathrm{N}$ ). Therefore, MC-GC synapses are less surrounded by MGL-expressing elements than pyramidal cell synapses. This different milieu is mainly caused by the lack of MGL expression in MC terminals, will prolong the half-life of 2-AG, and will increase its spread in the MC-recipient molecular layer of the dentate gyrus. In this regard, we also need to consider possible participation of other degrading enzymes, such as $\alpha / \beta$-hydrolases 6 and 12 (Blankman et al., 2007), although their functional contribution to 2-AG degradation appears much lower than MGL (Straiker et al., 2009; Marrs et al., 2010).

Moreover, our data from the serial electron microscopy have demonstrated that a given GC spine was not only innervated by a single MC terminal but also contacted nonsynaptically by one to three MC terminals that make synapses with other GC spines. There was only a narrow extracellular space between such GC spines and noninnervating MC terminals (Fig. 10). This molecular-anatomical configuration strongly suggests that, once liberated from activated GC spines, 2-AG is readily accessible not only to the activated MC terminal but also to nearby MC-GC synapses by escaping from enzymatic degradation (Fig. 11). This will cause 2-AG-mediated cross talk to local $\mathrm{CB}_{1}$-expressing synapses in the MC-recipient molecular layer, most likely other MC-GC synapses.

\section{Functional relevance of 2-AG-mediated retrograde signaling and cross talk in the MC-recipient molecular layer}

Such an eCB-mediated intersynaptic cross talk has been shown to occur in the hippocampal CA1; depolarization of a postsynaptic neuron induces DSI not only in the depolarized neuron, but also in nondepolarized neurons, if the depolarized neuron is apart $<20 \mu \mathrm{m}$ (Wilson and Nicoll, 2001). In contrast, in the cerebellum, synaptically evoked eCB-mediated DSE is confined to activated parallel fiber-Purkinje cell synapses (Brown et al., 2003; Brenowitz and Regehr, 2005). The limited cross talk in Purkinje cell synapses is likely attributable to complete synaptic coverage by Bergmann glia (Palay and Chan-Palay, 1974; Spacek, 1985) and high MGL contents in parallel fiber terminals (Gulyas et al., 2004). Thus, the extent of 2-AG-mediated intersynaptic cross talk (or input specificity) may vary from synapse to synapse depending on the constellation of 2-AG-mediated signaling molecules around synapses and the anatomical organization of presynaptic, postsynaptic, and glial elements. In this regard, our findings in the present study suggest that MC-GC synapses are more prone to 2-AG-mediated intersynaptic cross talk than pyramidal cell synapses in the hippocampus. This needs to be tested in future studies.

MCs are highly excitable, albeit subject to synaptic inhibition (Buckmaster and Schwartzkroin, 1994). Recurrent circuits from MCs to GCs are positioned between the entorhinal cortex and the hippocampal CA3, and are thought to regulate the excitability of the limbic system (Ratzliff et al., 2002). Furthermore, poor astrocytic coverage suggests that MC-GC synapses are also prone to glutamate spillover to neighboring synapses (Oliet et al., 2004). On one hand, these anatomical and physiological properties should be advantageous to normal hippocampal function, but on the other hand, the very same features might render these neurons and circuits hyperexcitable and vulnerable to excitotoxicity. 2-AG-mediated retrograde signaling and local cross talk at MC-GC synapses may contribute to suppressing the excitability of GCs and prevent seizures. When network activities are also increased, such cross talk could involve $\mathrm{CB}_{1}$-expressing inhibitory synapses, and the resultant DSI may increase seizure susceptibility and deteriorate the status epilepticus. Thus, it seems likely that MC-GC synapses are so constructed to permit, or even facilitate, 2-AG-mediated retrograde signaling and cross talk to adjust the excitability of this epileptogenic circuit (Ratzliff et al., 2002).

\section{References}

Bisogno T, Howell F, Williams G, Minassi A, Cascio MG, Ligresti A, Matias I, Schiano-Moriello A, Paul P, Williams EJ, Gangadharan U, Hobbs C, Di Marzo V, Doherty P (2003) Cloning of the first sn1-DAG lipases points to the spatial and temporal regulation of endocannabinoid signaling in the brain. J Cell Biol 163:463-468.

Blankman JL, Simon GM, Cravatt BF (2007) A comprehensive profile of brain enzymes that hydrolyze the endocannabinoid 2-arachidonoylglycerol. Chem Biol 14:1347-1356.

Blasco-Ibanez JM, Freund TF (1997) Distribution, ultrastructure, and connectivity of calretinin-immunoreactive mossy cells of the mouse dentate gyrus. Hippocampus 7:307-320.

Brenowitz SD, Regehr WG (2005) Associative short-term synaptic plasticity mediated by endocannabinoids. Neuron 45:419-431.

Brown SP, Brenowitz SD, Regehr WG (2003) Brief presynaptic bursts evoke synapse-specific retrograde inhibition mediated by endogenous cannabinoids. Nat Neurosci 6:1048-1057.

Buckmaster PS, Schwartzkroin PA (1994) Hippocampal mossy cell function: a speculative view. Hippocampus 4:393-402.

Capani F, Martone ME, Deerinck TJ, Ellisman MH (2001) Selective localization of high concentrations of F-actin in subpopulations of dendritic spines in rat central nervous system: a three-dimensional electron microscopic study. J Comp Neurol 435:156-170.

Chávez AE, Chiu CQ, Castillo PE (2010) TRPV1 activation by endogenous anandamide triggers postsynaptic long-term depression in dentate gyrus. Nat Neurosci 13:1511-1518.

Chiu CQ, Castillo PE (2008) Input-specific plasticity at excitatory synapses mediated by endocannabinoids in the dentate gyrus. Neuropharmacology $54: 68-78$

Dinh TP, Carpenter D, Leslie FM, Freund TF, Katona I, Sensi SL, Kathuria S, Piomelli D (2002) Brain monoglyceride lipase participating in endocannabinoid inactivation. Proc Natl Acad Sci U S A 99:10819-10824.

Fiala JC (2005) Reconstruct: a free editor for serial section microscopy. J Microsc 218:52-61.

Fujise N, Liu Y, Hori N, Kosaka T (1998) Distribution of calretinin immunoreactivity in the mouse dentate gyrus: II. Mossy cells, with special reference to their dorsoventral difference in calretinin immunoreactivity. Neuroscience 82:181-200.

Fukaya M, Watanabe M (2000) Improved immunohistochemical detection of postsynaptically located PSD-95/SAP90 protein family by protease section pretreatment: a study in the adult mouse brain. J Comp Neurol 426:572-586.

Fukaya M, Tsujita M, Yamazaki M, Kushiya E, Abe M, Akashi K, Natsume R, Kano M, Kamiya H, Watanabe M, Sakimura K (2006) Abundant distribution of TARP gamma-8 in synaptic and extrasynaptic surface of hip- 
pocampal neurons and its major role in AMPA receptor expression on spines and dendrites. Eur J Neurosci 24:2177-2190.

Fukaya M, Uchigashima M, Nomura S, Hasegawa Y, Kikuchi H, Watanabe M (2008) Predominant expression of phospholipase Cbetal in telencephalic principal neurons and cerebellar interneurons, and its close association with related signaling molecules in somatodendritic neuronal elements. Eur J Neurosci 28:1744-1759.

Fukudome Y, Ohno-Shosaku T, Matsui M, Omori Y, Fukaya M, Tsubokawa H, Taketo MM, Watanabe M, Manabe T, Kano M (2004) Two distinct classes of muscarinic action on hippocampal inhibitory synapses: M2mediated direct suppression and M1/M3-mediated indirect suppression through endocannabinoid signalling. Eur J Neurosci 19:2682-2692.

Fuse T, Kanai Y, Kanai-Azuma M, Suzuki M, Nakamura K, Mori H, Hayashi Y, Mishina M (2004) Conditional activation of RhoA suppresses the epithelial to mesenchymal transition at the primitive streak during mouse gastrulation. Biochem Biophys Res Commun 318:665-672.

Gao Y, Vasilyev DV, Goncalves MB, Howell FV, Hobbs C, Reisenberg M, Shen R, Zhang M-Y, Strassle BW, Lu P, Mark L, Piesla MJ, Deng K, Kouranova EV, Ring RH, Whiteside GT, Bates B, Walsh FS, Williams G, Pangalos MN, et al. (2010) Loss of retrograde endocannabinoid signaling and reduced adult neurogenesis in diacylglycerol lipase knock-out mice. J Neurosci 30:2017-2024.

Gulyas AI, Cravatt BF, Bracey MH, Dinh TP, Piomelli D, Boscia F, Freund TF (2004) Segregation of two endocannabinoid-hydrolyzing enzymes into pre- and postsynaptic compartments in the rat hippocampus, cerebellum and amygdala. Eur J Neurosci 20:441-458.

Harris KM, Kater SB (1994) Dendritic spines: cellular specializations imparting both stability and flexibility to synaptic function. Annu Rev Neurosci 17:341-371.

Hashimotodani Y, Ohno-Shosaku T, Tsubokawa H, Ogata H, Emoto K, Maejima T, Araishi K, Shin HS, Kano M (2005) Phospholipase Cbeta serves as a coincidence detector through its $\mathrm{Ca} 2+$ dependency for triggering retrograde endocannabinoid signal. Neuron 45:257-268.

Hashimotodani Y, Ohno-Shosaku T, Kano M (2007a) Presynaptic monoacylglycerol lipase activity determines basal endocannabinoid tone and terminates retrograde endocannabinoid signaling in the hippocampus. J Neurosci 27:1211-1219.

Hashimotodani Y, Ohno-Shosaku T, Kano M (2007b) Endocannabinoids and synaptic function in the CNS. Neuroscientist 13:127-137.

Hermann A, Kaczocha M, Deutsch DG (2006) 2-Arachidonoylglycerol (2AG) membrane transport: history and outlook. AAPS J 8:E409-412.

Hisano K, Watanabe M, Morimoto Y (2009) Protective effects of the free radical scavenger edaravone against glutamate neurotoxicity in nearly pure neuronal culture. J Anesth 23:363-369.

Hofmann ME, Nahir B, Frazier CJ (2006) Endocannabinoid-mediated depolarization-induced suppression of inhibition in hilar mossy cells of the rat dentate gyrus. J Neurophysiol 96:2501-2512.

Kano M, Ohno-Shosaku T, Hashimotodani Y, Uchigashima M, Watanabe M (2009) Endocannabinoid-mediated control of synaptic transmission. Physiol Rev 89:309-380.

Karlsson M, Contreras JA, Hellman U, Tornqvist H, Holm C (1997) cDNA cloning, tissue distribution, and identification of the catalytic triad of monoglyceride lipase. Evolutionary relationship to esterases, lysophospholipases, and haloperoxidases. J Biol Chem 272:27218-27223.

Katona I, Freund TF (2008) Endocannabinoid signaling as a synaptic circuit breaker in neurological disease. Nat Med 14:923-930.

Katona I, Sperlagh B, Sik A, Kafalvi A, Vizi ES, Mackie K, Freund TF (1999) Presynaptically located CB1 cannabinoid receptors regulate GABA release from axon terminals of specific hippocampal interneurons. J Neurosci 19:4544-4558.

Katona I, Urban GM, Wallace M, Ledent C, Jung KM, Piomelli D, Mackie K, Freund TF (2006) Molecular composition of the endocannabinoid system at glutamatergic synapses. J Neurosci 26:5628-5637.

Kawamura Y, Fukaya M, Maejima T, Yoshida T, Miura E, Watanabe M, Ohno-Shosaku T, Kano M (2006) The CB1 cannabinoid receptor is the major cannabinoid receptor at excitatory presynaptic sites in the hippocampus and cerebellum. J Neurosci 26:2991-3001.

Kreitzer AC, Regehr WG (2001) Retrograde inhibition of presynaptic calcium influx by endogenous cannabinoids at excitatory synapses onto Purkinje cells. Neuron 29:717-727.

Lujan R, Nusser Z, Roberts JD, Shigemoto R, Somogyi P (1996) Perisynaptic location of metabotropic glutamate receptors mGluR1 and mGluR5 on dendrites and dendritic spines in the rat hippocampus. Eur J Neurosci 8:1488-1500.

Maejima T, Hashimoto K, Yoshida T, Aiba A, Kano M (2001) Presynaptic inhibition caused by retrograde signal from metabotropic glutamate to cannabinoid receptors. Neuron 31:463-475.

Marrs WR, Blankman JL, Horne EA, Thomazeau A, Lin YH, Coy J, Bodor AL, Muccioli GG, Hu SS, Woodruff G, Fung S, Lafourcade M, Alexander JP, Long JZ, Li W, Xu C, Möller T, Mackie K, Manzoni OK Cravatt BF, et al. (2010) The serine hydrolase ABHD6 controls the accumulation and efficacy of 2-AG at cannabinoid receptors. Nat Neurosci 13:951-957.

Marsicano G, Goodenough S, Monory K, Hermann H, Eder M, Cannich A, Azad SC, Cascio MG, Gutierrez SO, van der Stelt M, Lopez-Rodriguez ML, Casanova E, Schutz G, Zieglgansberger W, Di Marzo V, Behl C, Lutz B (2003) CB1 cannabinoid receptors and on-demand defense against excitotoxicity. Science 302:84-88.

Mechoulam R, Ben-Shabat S, Hanus L, Ligumsky M, Kaminski NE, Schatz AR, Gopher A, Almog S, Martin BR, Compton DR, et al (1995) Identification of an endogenous 2-monoglyceride, present in canine gut, that binds to cannabinoid receptors. Biochem Pharmacol 50:83-90.

Mishina M, Sakimura K (2007) Conditional gene targeting on the pure C57BL/6 genetic background. Neurosci Res 58:105-112.

Miura E, Fukaya M, Sato T, Sugihara K, Asano M, Yoshioka K, Watanabe M (2006) Expression and distribution of JNK/SAPK-associated scaffold protein JSAP1 in developing and adult mouse brain. J Neurochem 97:1431-1446.

Miyazaki T, Fukaya M, Shimizu H, Watanabe M (2003) Subtype switching of vesicular glutamate transporters at parallel fibre-Purkinje cell synapses in developing mouse cerebellum. Eur J Neurosci 17:2563-2572.

Miyazaki T, Yamasaki M, Uchigashima M, Matsushima A, Watanabe M (2011) Cellular expression and subcellular localization of secretogranin II in the mouse hippocampus and cerebellum. Eur J Neurosci 33:82-94.

Monory K, Massa F, Egertová M, Eder M, Blaudzun H, Westenbroek R, Kelsch W, Jacob W, Marsch R, Ekker M, Long J, Rubenstein JL, Goebbels S, Nave KA, During M, Klugmann M, Wölfel B, Dodt HU, Zieglgänsberger W, Wotjak CT, et al. (2006) The endocannabinoid system controls key epileptogenic circuits in the hippocampus. Neuron 51:455-466.

Nakamura K, Manabe T, Watanabe M, Mamiya T, Ichikawa R, Kiyama Y, Sanbo M, Yagi T, Inoue Y, Nabeshima T, Mori H, Mishina M (2001) Enhancement of hippocampal LTP, reference memory and sensorimotor gating in mutant mice lacking a telencephalon-specific cell adhesion molecule. Eur J Neurosci 13:179-189.

Nakamura M, Sato K, Fukaya M, Araishi K, Aiba A, Kano M, Watanabe M (2004) Signaling complex formation of phospholipase Cbeta4 with metabotropic glutamate receptor type 1alpha and 1,4,5-trisphosphate receptor at the perisynapse and endoplasmic reticulum in the mouse brain. Eur J Neurosci 20:2929-2944.

Narushima M, Uchigashima M, Fukaya M, Matsui M, Manabe T, Hashimoto K, Watanabe M, Kano M (2007) Tonic enhancement of endocannabinoidmediated retrograde suppression of inhibition by cholinergic interneuron activity in the striatum. J Neurosci 27:496-506.

Ohno-Shosaku T, Maejima T, Kano M (2001) Endogenous cannabinoids mediate retrograde signals from depolarized postsynaptic neurons to presynaptic terminals. Neuron 29:729-738.

Ohno-Shosaku T, Shosaku J, Tsubokawa H, Kano M (2002) Cooperative endocannabinoid production by neuronal depolarization and group I metabotropic glutamate receptor activation. Eur J Neurosci 15:953-961.

Oliet SH, Piet R, Poulain DA, Theodosis DT (2004) Glial modulation of synaptic transmission: Insights from the supraoptic nucleus of the hypothalamus. Glia 47:258-267.

Palay S, Chan-Palay V (1974) Cerebellar cortex. New York: Springer.

Pan B, Wang W, Long JZ, Sun D, Hillard CJ, Cravatt BF, Liu QS (2009) Blockade of 2-arachidonoylglycerol hydrolysis by selective monoacylglycerol lipase inhibitor 4-nitrophenyl 4-(dibenzo[d] [1,3] dioxol-5-yl(hydroxy)methyl)piperidine-1-carboxylate (JZL184) Enhances retrograde endocannabinoid signaling. J Pharmacol Exp Ther 331:591-597.

Peters A, Palay S, Webster H (1976) The fine structure of the nervous system. Philadelphia: Saunders.

Ratzliff AH, Santhakumar V, Howard A, Soltesz I (2002) Mossy cells in epilepsy: rigor mortis or vigor mortis? Trends Neurosci 25:140-144.

Schlosburg JE, Blankman JL, Long JZ, Nomura DK, Pan B, Kinsey SG, Nguyen PT, Ramesh D, Booker L, Burston JJ, Thomas EA, Selley DE, Sim-Selley LJ, Liu QS, Lichtman AH, Cravatt BF (2010) Chronic mono- 
acylglycerol lipase blockade causes functional antagonism of the endocannabinoid system. Nat Neurosci 13:1113-1119.

Shepherd G (2004) The synaptic organization of the brain, Ed 5. New York: Oxford UP.

Shibata T, Yamada K, Watanabe M, Ikenaka K, Wada K, Tanaka K, Inoue Y (1997) Glutamate transporter GLAST is expressed in the radial glia-astrocyte lineage of developing mouse spinal cord. J Neurosci 17:9212-9219.

Soussi R, Zhang N, Tahtakran S, Houser CR, Esclapez M (2010) Heterogeneity of the supramammillary-hippocampal pathways: evidence for a unique GABAergic neurotransmitter phenotype and regional differences. Eur J Neurosci 32:771-785.

Spacek J (1985) Three-dimensional analysis of dendritic spines. III. Glial sheath. Anat Embryol (Berl) 171:245-252.

Stella N, Schweitzer P, Piomelli D (1997) A second endogenous cannabinoid that modulates long-term potentiation. Nature 388:773-778.

Straiker A, Hu SS, Long JZ, Arnold A, Wager-Miller J, Cravatt BF, Mackie K (2009) Monoacylglycerol lipase limits the duration of endocannabinoidmediated depolarization-induced suppression of excitation in autaptic hippocampal neurons. Mol Pharmacol 76:1220-1227.

Sugiura T, Kondo S, Sukagawa A, Nakane S, Shinoda A, Itoh K, Yamashita A, Waku K (1995) 2-Arachidonoylglycerol: a possible endogenous cannabinoid receptor ligand in brain. Biochem Biophys Res Commun 215:89-97.

Tanaka J, Nakagawa S, Kushiya E, Yamasaki M, Fukaya M, Iwanaga T, Simon MI, Sakimura K, Kano M, Watanabe M (2000) Gq protein alpha subunits Galphaq and Galpha11 are localized at postsynaptic extra-junctional membrane of cerebellar Purkinje cells and hippocampal pyramidal cells. Eur J Neurosci 12:781-792.

Tanimura A, Yamazaki M, Hashimotodani Y, Uchigashima M, Kawata S, Abe M, Kita Y, Hashimoto K, Shimizu T, Watanabe M, Sakimura K, Kano M (2010) The endocannabinoid 2-arachidonoylglycerol produced by diacylglycerol lipase alpha mediates retrograde suppression of synaptic transmission. Neuron 65:320-327.

Uchigashima M, Narushima M, Fukaya M, Katona I, Kano M, Watanabe M (2007a) Subcellular arrangement of molecules for 2-arachidonoylglycerol-mediated retrograde signaling and its physiological contribution to synaptic modulation in the striatum. J Neurosci 27:3663-3676.
Uchigashima M, Fukaya M, Watanabe M, Kamiya H (2007b) Evidence against GABA release from glutamatergic mossy fiber terminals in the developing hippocampus. J Neurosci 27:8088-8100.

Varma N, Carlson GC, Ledent C, Alger BE (2001) Metabotropic glutamate receptors drive the endocannabinoid system in hippocampus. J Neurosci 21:RC188(1-5)

Wallace MJ, Blair RE, Falenski KW, Martin BR, DeLorenzo RJ (2003) The endogenous cannabinoid system regulates seizure frequency and duration in a model of temporal lobe epilepsy. J Pharmacol Exp Ther 307:129-137.

Walter L, Dinh T, Stella N (2004) ATP induces a rapid and pronounced increase in 2-arachidonoylglycerol production by astrocytes, a response limited by monoacylglycerol lipase. J Neurosci 24:8068-8074.

Watanabe M, Fukaya M, Sakimura K, Manabe T, Mishina M, Inoue Y (1998) Selective scarcity of NMDA receptor channel subunits in the stratum lucidum (mossy fibre-recipient layer) of the mouse hippocampal CA3 subfield. Eur J Neurosci 10:478-487.

Wettschureck N, van der Stelt M, Tsubokawa H, Krestel H, Moers A, Petrosino S, Schutz G, Di Marzo V, Offermanns S (2006) Forebrainspecific inactivation of Gq/G11 family $G$ proteins results in agedependent epilepsy and impaired endocannabinoid formation. Mol Cell Biol 26:5888-5894.

Wilson RI, Nicoll RA (2001) Endogenous cannabinoids mediate retrograde signalling at hippocampal synapses. Nature 410:588-592.

Yamasaki M, Matsui M, Watanabe M (2010) Preferential localization of muscarinic M1 receptor on dendritic shaft and spine of cortical pyramidal cells and its anatomical evidence for volume transmission. J Neurosci 30:4408-4418.

Yamazaki M, Fukaya M, Hashimoto K, Yamasaki M, Tsujita M, Itakura M, Abe M, Natsume R, Takahashi M, Kano M, Sakimura K, Watanabe M (2010) TARPs gamma-2 and gamma-7 are essential for AMPA receptor expression in the cerebellum. Eur J Neurosci 31:2204-2220.

Yoshida T, Fukaya M, Uchigashima M, Miura E, Kamiya H, Kano M, Watanabe M (2006) Localization of diacylglycerol lipase-alpha around postsynaptic spine suggests close proximity between production site of an endocannabinoid, 2-arachidonoyl-glycerol, and presynaptic cannabinoid CB1 receptor. J Neurosci 26:4740-4751. 